\title{
Mini-Stern Trial: A randomized trial comparing mini-sternotomy to full median sternotomy for aortic valve replacement
}

Sukumaran K. Nair, FRCS(CTh) ${ }^{a, b}$ Catherine D. Sudarshan, FRCS(CTh), ${ }^{a}$ Benjamin S. Thorpe, PhD, ${ }^{c}$ Jeshika Singh, PhD ${ }^{\mathrm{d}}$ Thasee Pillay, FRCS(CTh), ${ }^{\mathrm{b}}$ Pedro Catarino, FRCS(CTh), ${ }^{\mathrm{a}}$ Kamen Valchanov, MD, ${ }^{\mathrm{a}}$ Massimiliano Codispoti, FRCS(CTh), ${ }^{a}$ John Dunning, FRCS(CTh), ${ }^{a}$ Yasir Abu-Omar, FRCS(CTh), ${ }^{a}$ Narain Moorjani, FRCS(CTh), ${ }^{\text {a }}$ Claire Matthews, BSc, ${ }^{\text {a }}$ Carol J. Freeman, MPhil, ${ }^{a}$ Julia A. Fox-Rushby, $\mathrm{PhD},{ }^{\mathrm{d}}$ and Linda D. Sharples, $\mathrm{PhD}^{\mathrm{e}}$

\section{ABSTRACT}

Objective: Aortic valve replacement (AVR) can be performed either through full median sternotomy (FS) or upper mini-sternotomy (MS). The Mini-Stern trial aimed to establish whether MS leads to quicker postoperative recovery and shorter hospital stay after first-time isolated AVR.

Methods: This pragmatic, open-label, parallel randomized controlled trial (RCT) compared MS with FS for first-time isolated AVR in 2 United Kingdom National Health Service hospitals. Primary endpoints were duration of postoperative hospital stay and the time to fitness for discharge from hospital after AVR, analyzed in the intent-to-treat population.

Results: In this RCT, 222 patients were recruited and randomized ( $\mathrm{n}=118$ in the MS group; $n=104$ in the FS group). Compared with the FS group, the MS group had a longer hospital length of stay (mean, 9.5 days vs 8.6 days) and took longer to achieve fitness for discharge home (mean, 8.5 days vs 7.5 days). Adjusting for valve type, sex, and surgeon, hazard ratios (HRs) from Cox models did not show a statistically significant effect of MS (relative to FS) on either hospital stay (HR, 0.874; 95\% confidence interval [CI], 0.668-1.143; $P=.3246$ ) or time to fitness for discharge (HR, 0.907; 95\% CI, 0.688-1.197; $P$ value $=.4914)$. During a mean follow-up of 760 days (745 days for the MS group and 777 days for the FS group), 12 patients $(10 \%)$ in the MS group and 7 patients $(7 \%)$ in the FS group died (HR, 1.871; 95\% CI, 0.723-4.844; $P=.1966)$. Average extra cost for MS was $£ 1714$ during the first 12 months after AVR.

Conclusions: Compared with FS for AVR, MS did not result in shorter hospital stay, faster recovery, or improved survival and was not cost-effective. The MS approach is not superior to FS for performing AVR. (J Thorac Cardiovasc Surg 2018;156:2124-32)

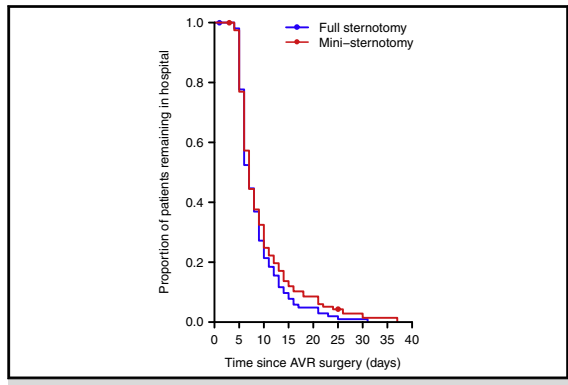

Duration of hospital stay after aortic valve replacement: full median sternotomy versus mini-sternotomy.

\section{Central Message}

In the United Kingdom's National Health Service, compared with a conventional median sternotomy approach for surgical aortic valve replacement, mini-sternotomy did not hasten recovery or hospital discharge and was not cost-effective.

\section{Perspective}

Minimal access surgery is appealing for its perceived advantages, including better patient recovery, satisfaction, and cost-effectiveness. This randomized controlled trial conducted within the United Kingdom's National Health Service setting did not demonstrate quicker patient recovery or cost-effectiveness associated with mini-sternotomy compared with a full median sternotomy approach. These findings are relevant to physicians, patients, and health care funders.

See Editorial Commentary page 2133.

\footnotetext{
From the a Department of Cardiothoracic Surgery, Papworth Hospital, Cambridge, United Kingdom; ' Freeman Hospital, Newcastle upon Tyne, United Kingdom; ${ }^{c}$ Leeds Institute of Clinical Trials Research, University of Leeds, Leeds, United Kingdom; ${ }^{\mathrm{d}}$ Health Economics Research Group, Brunel University London, London, United Kingdom; and ${ }^{\mathrm{e}}$ London School of Hygiene and Tropical Medicine, Keppel Street, London, United Kingdom.

This work was supported by the National Institute for Health Research (NIHR) under its Research for Patient Benefit (RfPB) Programme (Grant PB-PG-0408-16296). The views expressed are those of the authors and not necessarily those of the National Health Service, NIHR, or Department of Health. The work of L.S. was partially funded by the Medical Research Council.
}

\footnotetext{
National Research Ethics Service Approval: 09/H0301/58 Trial Registration: ISRCTN, no. 58128724

Received for publication Dec 17, 2017; revisions received April 23, 2018; accepted for publication May 15, 2018; available ahead of print July 31, 2018.

Address for reprints: Sukumaran K. Nair, FRCS(CTh), Consultant Cardiac Surgeon, Golden Jubilee National Hospital, Agamemnon St, Glasgow G81 4DY, United Kingdom (E-mail: Sukumaran.Nair@gjnh.scot.nhs.uk). $0022-5223 / \$ 36.00$

Copyright (C) 2018 by The American Association for Thoracic Surgery https://doi.org/10.1016/j.jtcvs.2018.05.057
} 

Abbreviations and Acronyms
AVR = aortic valve replacement
$\mathrm{CI}=$ confidence interval
$\mathrm{CPB}=$ cardiopulmonary bypass
FS = full median sternotomy
HR = hazard ratio
HRQoL $=$ health-related quality of life
mAVR $=$ minimal access aortic valve replacement
MS = mini-sternotomy
NHS = National Health Service
OR = odds ratio
QALY = quality-adjusted life-year
$\mathrm{RCT}=$ randomized controlled trial
$\mathrm{SAE}=$ serious adverse event
SF-36 = Short Form Health Survey
TOE $=$ transoesophageal echocardiography

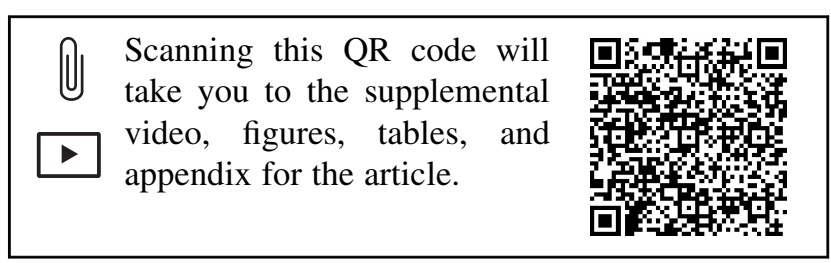

Aortic valve replacement (AVR) is the second most frequent cardiac surgery in the United Kingdom, ${ }^{1}$ which has an ever-increasing proportion of older patients. ${ }^{1,2}$ Minimal access AVR (mAVR) might shorten the hospital stay and the postoperative recovery period and could be beneficial if offered safely and cost-effectively.

Currently, most AVRs are performed safely through full median sternotomy (FS). ${ }^{2-6}$ However, mAVR may be associated with less postoperative pain and blood loss, fewer pulmonary and wound complications, and a shorter hospital stay. ${ }^{2}$ The most common mAVR technique involves a mini-sternotomy (MS), which could potentially hasten postoperative recovery, shorten hospital stay and improve patient satisfaction. ${ }^{2-10}$

Most previous studies comparing MS and FS for AVR were nonrandomized. Although systematic reviews with meta-analyses $^{11,12}$ have been conducted, inadequate statistical power and heterogeneity of studies calls for prospective, randomized controlled trials (RCTs) to assess the benefits and risks of mAVR. Published evidence on cost-effectiveness comparing MS and FS is sparse and weak. A recent review comparing the cost-effectiveness of FS and MS called for a well-designed RCT to evaluate the cost-effectiveness of mAVR up to at least 1 year after surgery. ${ }^{13}$ A recent propensity-matched study from United Kingdom national data concluded that mAVR is safe and associated with shorter postoperative hospital stay. ${ }^{14}$ The authors concluded that although general clinical equipoise exists between FS and MS, a well-constructed and adequately powered RCT is essential before widespread adoption of MS. That retrospective study did not analyze the cost-effectiveness of either surgical approach, however.

The Mini-Stern trial assessed whether MS is superior to FS in shortening postoperative recovery time and improving patient outcomes without compromising patient safety. It also assessed the cost-effectiveness of MS from the perspective of the United Kingdom's National Health Service (NHS) as a health care provider.

\section{MATERIALS AND METHODS}

Mini-Stern was a 2-center, pragmatic, open-label RCT conducted in the United Kingdom. Patients were randomized (1:1) to AVR by either MS or FS.

\section{Sample Size}

In 4 published RCTs ${ }^{5,6,9,10}$ and 2 cohort studies, ${ }^{7,8}$ a $20 \%$ reduction in median length of hospital stay from 11.7 to 9.36 days was considered clinically significant. Based on an internal audit of 252 first-time elective AVRs performed at Papworth Hospital in 2007 to 2008 (mean hospital length of stay, 11.7 [6.2] days), to detect this change with $80 \%$ power and 2-sided significance of 5\%, 110 patients per group were required. Because randomization was performed on the day of surgery after induction of anesthesia and introduction of the transesophageal echocardiography (TOE) probe, no subjects dropped out between randomization and surgery, thereby achieving the total trial recruitment target of 220 patients.

\section{Recruitment}

Adult patients undergoing first-time isolated AVR were included. Exclusion criteria included emergency AVR, left ventricular ejection fraction $\leq 30 \%$, chest wall deformities, severe chronic obstructive pulmonary disease (forced expiratory volume in 1 second or transfer factor of the lung for carbon monoxide $<40 \%$ of predicted), body mass index $>35 \mathrm{~kg} / \mathrm{m}^{2}$, concomitant cardiac surgery, redo surgery, and inability to perform TOE. Details of patient enrolment are given in the online protocol.

\section{Randomization}

Randomization (1:1) used random permuted blocks of variable lengths (6 or 8 ), stratified by surgeon and valve prosthesis (bioprosthetic or mechanical). Random allocations were pregenerated, held in secure files by the Papworth Trials Unit. During early days of the trial, TOE probe could not be passed in 4 patients due to technical reasons. These patients underwent the allocated procedure and were included in the trial. Subsequently, the Trial Steering Committee determined that under such circumstances, MS would be unsafe, and patients should be excluded from the trial to FS. Because eligibility for MS required TOE, to avoid postrandomization dropout, group allocation for the study subjects was retrieved via telephone by theatre staff soon after induction of anesthesia and introduction of the TOE probe. Owing to the nature of the interventions, this trial could not be blinded.

\section{Outcomes}

Primary endpoints. Two closely related primary endpoints were measured: (1) length of postoperative hospital stay (ie, days between surgery and actual hospital discharge) which is easily measured, a surrogate for early postoperative events and sensitive to outcomes that 


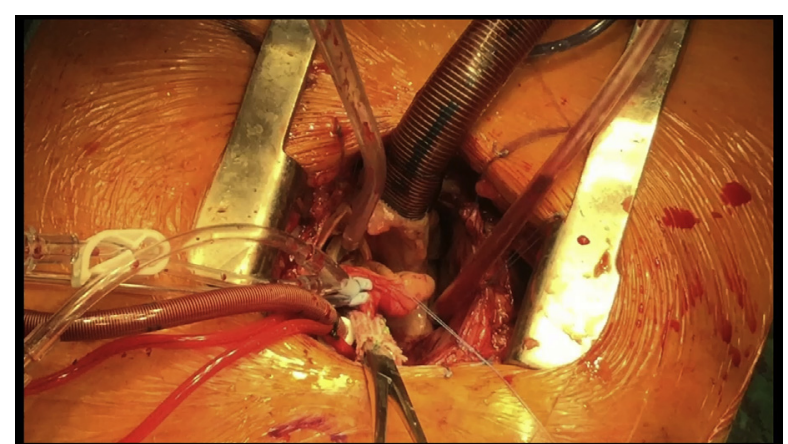

VIDEO 1. Mini-sternotomy approach for aortic valve replacement. Video available at: https://www.jtcvs.org/article/S0022-5223(18)31482X/fulltext.

affect health-related quality of life (HRQoL); and (2) the interval between surgery and the patient being medically fit for discharge (in days). To reduce investigator bias, standard discharge criteria were followed to determine the day of fitness for discharge. This endpoint was chosen to address exogenous effects (eg, social factors, lack of transport, nonavailability of space in nursing homes) that commonly delay hospital discharge in the United Kingdom.

Secondary endpoints. Clinical secondary endpoints included duration of surgery, total theatre time, aortic cross-clamp and cardiopulmonary bypass $(\mathrm{CPB})$ times, blood loss in the first 12 hours after surgery, transfusion of blood and clotting products in the first 48 hours (the blood transfusion trigger was a hemoglobin level $<80 \mathrm{~g} / \mathrm{L}$ ), frequency of reintubation, time to initial extubation, mediastinal drain removal and first independent mobilization, daily pain scores at rest and on deep breathing (over the first 10 days or until hospital discharge) on a scale of 0 to 10 , left ventricular ejection fraction, severity of paraprosthetic regurgitation at hospital discharge and at 6 months, and time to all-cause death. Definitions of adverse events and details of their reporting are provided in the online protocol. To exclude bias, clinical outcome data were collected by a research team not involved in routine care of the subjects, following standardized protocols.

Nonclinical secondary endpoints included HRQoL and health care resource use.

HRQoL. Patients completed the EQ-5D-3L ${ }^{15}$ and Short Form Health Survey (SF-36) ${ }^{16,17}$ questionnaires at baseline and at 6 weeks, 6 months, and 12 months postsurgery. The EQ-5D-3L was repeated on the fourth postoperative day and at discharge.

Health care resource use. Patient-specific resource use data collected from hospital records and patient interviews during the primary admission included phases of care (operative surgery, critical care, and postsurgical ward care) and medication administration. Postdischarge resource use included attending wound clinics, community nurse visits, physiotherapy sessions, occupational therapy services, medical tests, cost of analgesics and other drugs, and further hospitalization within the first year after AVR.

\section{Surgical Details}

All participating surgeons were consultants experienced in performing AVR by both FS and MS. They followed the operative surgical protocol as described below. Video 1 shows the MS approach and is available in the online version of this article.

MS approach. With the patient anesthetized in accordance with standard protocol, skin was incised from halfway between the suprasternal notch and the sternal angle to the level of the fourth intercostal space, approximately $8 \mathrm{~cm}$. The manubrium was divided in the midline from the suprasternal notch inferiorly and then into the right fourth intercostal space. The thymus was divided and the pericardium was opened, exposing the ascending aorta, aortic root, and right atrial appendage. A $300 \mathrm{U} / \mathrm{kg}$ loading dose of unfractionated heparin followed by boluses of $5000 \mathrm{U}$ was administered to achieve activated clotting time $>450$ seconds. The aorta was cannulated using a wired flexible aortic cannula. The right atrial appendage was cannulated using a flat venous cannula, and CPB was initiated. The ascending aorta was cross-clamped and intermittent, antegrade, cold blood cardioplegia administered. The aorta was then incised open in an oblique or transverse fashion, the diseased valve was excised, and the annulus was decalcified. A suitably sized aortic valve prosthesis was inserted using either horizontal mattress 2-0 Ethibond sutures or semi-continuous 2-0 Prolene sutures. Surgeons adopted either of these suture techniques and adhered to the same technique irrespective of the type of valve prosthesis or the surgical approach. The aortotomy was then closed, the heart was deaired, right atrial and ventricular epicardial pacing wires were inserted, and the patient was weaned off $\mathrm{CPB}$. Once satisfactory functioning of the aortic valve prosthesis was confirmed by TOE, heparin was reversed with protamine $(1 \mathrm{mg} / 100 \mathrm{U}$ of heparin). Chest drains were inserted into the anterior mediastinum, posterior pericardial space, and pleural space as necessary. Sternal wires were inserted, and the incision was closed in layers. Conversion to FS was performed to ensure patient safety if access proved difficult or if intraoperative complications occurred.

FS approach. Anesthesia and positioning of patients was the same as for the MS approach. The skin incision was made between the suprasternal notch and the xiphoid process and sternum divided in the midline from the suprasternal notch to the xiphoid process. A 2-stage venous cannula was used for atrial cannulation. The remaining steps were similar to those for the MS approach.

\section{Statistical Analysis}

Analyses of primary and secondary endpoints used intention-to-treat and included all randomized patients. Unless stated otherwise, statistical models included treatment (MS vs FS), valve (mechanical vs bioprosthetic), and sex as fixed effects and surgeons as random effects. Hypothesis testing was 2-sided at a 5\% significance level, with no adjustments for multiple testing. All confidence intervals (CIs) were estimated at the $95 \%$ confidence level.

Distributions of time-to-event endpoints were compared between study groups using Kaplan-Meier curves and log-rank tests (stratified by sex, valve, and surgeon). Hazard ratios (HRs) for MS relative to FS were estimated from a Cox model. The null hypothesis of no treatment effect $(H R=1)$ was tested. Patients who were lost to follow-up, withdrew, or died before the event were censored at the latest time they were known to be event-free. Models were checked by plotting Schoenfeld and deviance residuals. For primary endpoints, Cox models were refitted using the per-protocol population and used in sensitivity analyses (Appendix E1, Table E4).

The need for reintubation and other dichotomous endpoints were compared between groups by estimating an MS/FS odds ratio (OR) via logistic regression. EQ-5D, SF-36, and pain scores were modeled using repeated-measures linear regression. When possible, random intercepts and random time coefficients for patients were included. For EQ-5D and SF-36, fixed effects for baseline scores were included. Models were fitted using complete cases, then refitted with multiple imputation of missing scores via chained equations.

Serious adverse events (SAEs) were analyzed in the safety population according to intervention received. Patients randomized to MS who crossed over to FS before surgery were considered to have received FS; those who crossed over after the initiation of MS were considered to have received MS. Rates of SAEs were explored using Poisson regression with a random patient effect.

CONSORT guidelines (Online Data Supplement and Figure E1) ${ }^{18}$ were followed. Analyses were performed in SAS version 9.4 (SAS Institute, Cary, NC). No interim analyses were conducted, but reports were presented annually to the Data Monitoring and Ethics Committee. 
TABLE 1. Baseline characteristics

\begin{tabular}{lcc}
\hline \multicolumn{1}{c}{ Characteristic } & MS $(\mathbf{n}=\mathbf{1 1 8})$ & FS $(\mathbf{n}=\mathbf{1 0 4})$ \\
\hline Age, $\mathrm{y}$, mean $(\mathrm{SD})$ & $71.3(12.3)$ & $72.1(10.9)$ \\
Body mass index, $\mathrm{kg} / \mathrm{m}^{2}$, mean (SD) & $26.6(3.2)$ & $27.7(3.7)$ \\
Sex, $\mathrm{n}(\%)$ & & \\
$\quad$ Female & $53(45)$ & $57(55)$ \\
$\quad$ Male & $65(55)$ & $47(45)$ \\
Valve type, \% & & \\
$\quad$ Mechanical & $15(13)$ & $14(13)$ \\
$\quad$ Tissue & $103(87)$ & $90(87)$ \\
EuroSCORE, \%, mean (SD) & $5.9(2.1)^{*}$ & $6.1(2.1)$ \\
\hline
\end{tabular}

$M S$, Mini-sternotomy; $F S$, full median sternotomy; $S D$, standard deviation. *EuroSCORE was missing for 1 patient in the MS group.

\section{Economic Analysis}

Unit costs were obtained from nationally published sources in the United Kingdom ${ }^{19-22}$ or from the Finance Department of Papworth Hospital when the former did not provide the required information. The total cost per patient was calculated by summing resource use items multiplied by unit costs across the in-patient stay and the 12-month postoperative follow-up period (Appendix E1, Table E22). Health state utilities from the EQ-5D$3 \mathrm{~L}$ and SF-36, based on United Kingdom value sets, ${ }^{15,23}$ were used to generate quality-adjusted life years (QALYs) using the area under the curve method and assigning a value of 0 from the date of death. Missing values were imputed using chained predictive mean matching, stratified by treatment and conditional on age, sex, and baseline EQ-5D-3L data.

Differences in mean costs and QALYs were estimated using seemingly unrelated regression, controlling for age, sex, valve type, baseline EQ-5D-3L, and treatment to accommodate skewness. ${ }^{24}$ Uncertainty in cost-effectiveness was estimated by drawing 1000 bootstrapped samples and conducting a probabilistic sensitivity analysis. Results are presented as incremental net monetary benefit at various thresholds of willingness to pay per QALY, cost-effectiveness planes, and cost-effectiveness acceptability curves. Deterministic sensitivity analyses explored the effects of using complete cases only, SF6D-based QALY estimates, and the procedure inpatient admission only and excluding patients who died and additional equipment costs (Appendix E1, Table E26).

\section{RESULTS}

A total of 1024 patients were screened between January 28, 2010, and April 13, 2015, of whom 222 were recruited and randomized to the MS $(\mathrm{n}=118)$ or FS $(\mathrm{n}=104)$ group. The 1-year follow-up was completed on May 23, 2016.

Study groups were similar at baseline except for a nonsignificant sex imbalance (Table 1). In this trial, MS was not completed in 14 of 118 patients randomized to MS (12\%). Of these patients, $6(5 \%)$ had a conversion from MS to FS owing to reasons listed in Figure 1. The remaining 8 patients underwent FS after randomization to MS but without an initial MS incision, because MS was considered unsafe or impractical. Thus, the true rate of intraoperative conversion of MS to FS was $5 \%$. Four patients $(2 \%)$ were censored before discharge, 1 patient who withdrew before surgery (FS group) and 3 patients who died (all randomized to and received MS) (Table 2). Another 13 patients $(6 \%)$ were censored before fitness for discharge, including 6 discharged to an acute hospital ( 3 in each group) and 7 discharged to long-term care or rehabilitation ( 3 in the FS group and 4 in the MS group).

The mean time to hospital discharge was longer in the MS group than in the FS group (9.5 days vs 8.6 days), as was mean time to fitness for discharge (8.5 days vs 7.5 days). The distributions of these endpoints were similar in the 2 groups, however (Figure 2 and Table 2). The difference was not statistically significant in primary analyses using Cox models (Figure 3), log-rank tests (Table 2), or sensitivity analyses (Table E4). The gamma-distributed frailty term in the Cox models was estimated to have a variance of 0.006675 for time to fitness and of 0.000100 for time to discharge, suggesting that surgeon heterogeneity was negligible.

The time to drain removal (including drains inserted/ retained to treat complications) was longer for the MS group, but times to extubation and independent mobilization did not differ significantly between the groups (Table 2 and Figure 3), nor did the number of patients reintubated (6 in the MS group vs 5 in the FS group; OR, $1.039 ; 95 \%$ CI, 0.306-3.531; $P=.9512$ ). Statistically significant HRs indicated longer duration of operative, $\mathrm{CPB}$, cross-clamp, and theatre times for the MS group (Figure 3). No significant between-group differences were seen in blood loss (Table E3) or in the number of patients requiring transfusion of blood (50 in the MS group vs 51 in the FS group; OR, $0.797 ; 95 \% \mathrm{CI}, 0.453-1.402 ; P=.4310$ ) or clotting products (11 in the MS group vs 4 in the FS group; OR, 2.616; 95\% CI, 0.801-8.541; $P=.1112$ ).

Regression models for pain at rest, EQ-5D utilities, and SF-36 domain scores (Tables E6-E8) estimated greater rates of improvement over time in MS patients for 3 SF-36 domains (social functioning, vitality, and role physical). After multiple imputation, the difference was only significant for the role physical domain (Table E9). Pain on deep breathing was not analyzed, because only less than one-half of the data were collected owing to poor patient compliance.

Nine patients $(4 \%)$ died within 1 year of surgery, including $7(6 \%)$ in the MS group and $2(2 \%)$ in the FS group. Five deaths were possibly related to treatment (4 in the MS group and 1 in the FS group), and none was likely or definitely related (Table E15). Overall, 12 patients $(10 \%)$ in the MS group and 7 patients $(7 \%)$ in the FS group died during follow-up (mean follow-up, 760 days; 745 days in the MS group and 777 days in the FS group). Time to all-cause death, adjusted for age, showed a moderately large but statistically nonsignificant HR (MS/FS) of 1.871 (95\% CI, 0.723-4.844; $P=.1966$ ).

Safety analyses excluded 1 patient who was withdrawn before surgery. There were significantly more SAEs in the MS recipients (rate ratio, 1.615; 95\% CI, 1.070-2.437; 


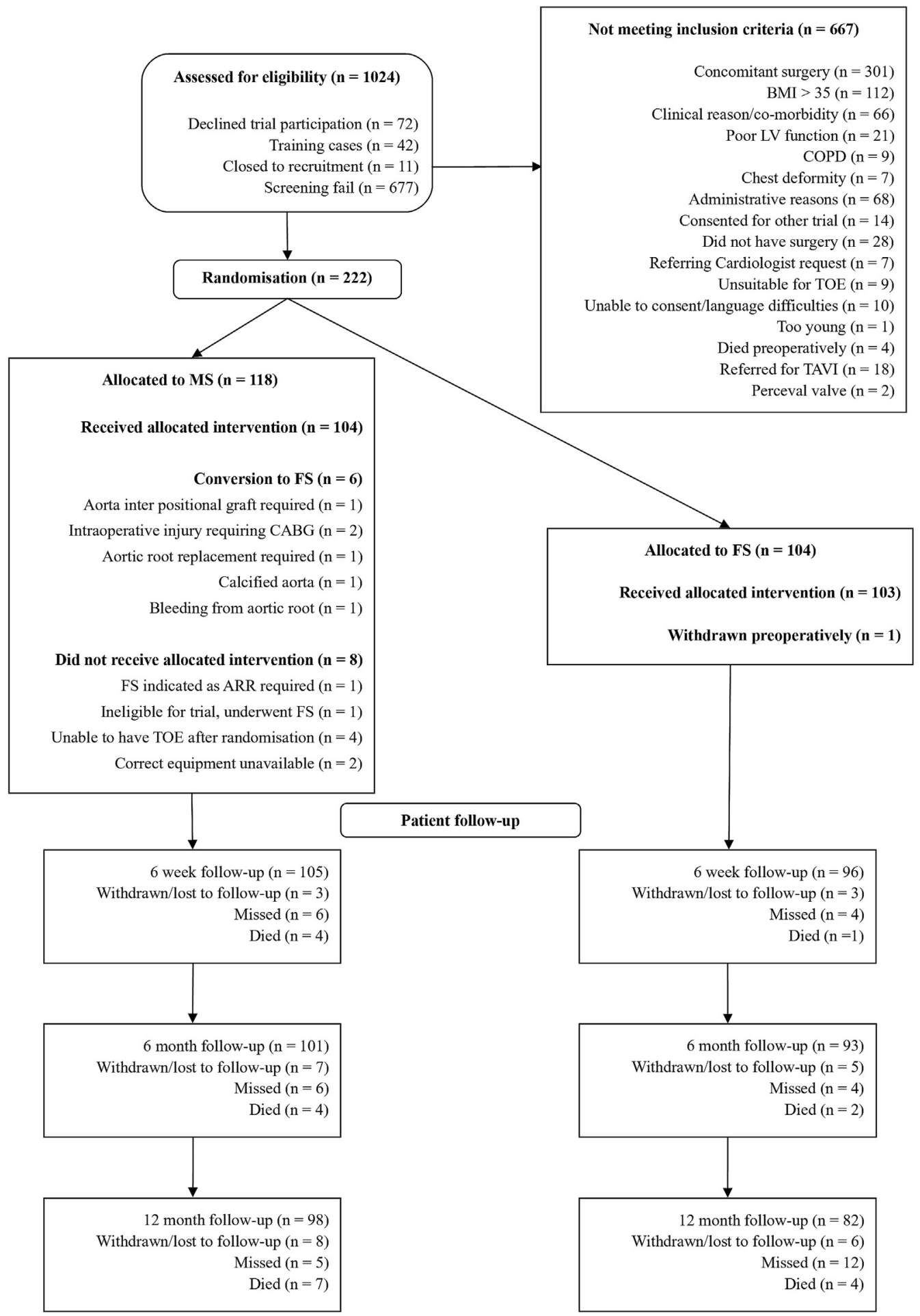

FIGURE 1. Trial flow diagram. $B M I$, Body mass index; $L V$, left ventricular; $C O P D$, chronic obstructive pulmonary/airway disease; $T O E$, transesophageal echocardiography; TAVI, transcutaneous aortic valve implantation; $M S$, mini-sternotomy; $F S$, full median sternotomy; $C A B G$, coronary artery bypass grafting; ARR, aortic root replacement.

$P=.0225$ ) (Table E11). The number of patients experiencing SAEs did not differ significantly between the 2 groups (OR, 1.559; 95\% CI, 0.895-2.715; $P=.1161)$. The incidence of paraprosthetic regurgitation did not differ significantly between the 2 groups (Table E13). Seven patients developed pericardial collection (3 in the MS group and 4 in the FS group; OR, $0.680 ; 95 \% \mathrm{CI}, 0.146-3.178 ; P=.6229)$. Wound infections 
TABLE 2. Kaplan-Meier medians (quartiles) for time-to-event endpoints

\begin{tabular}{|c|c|c|c|}
\hline Endpoint & $\operatorname{MS}(\mathbf{n}=118)$ & FS $(n=104)$ & $P$ value* \\
\hline Time to discharge (d) & $7(6-10)$ & $7(6-10)$ & .6924 \\
\hline Censored & 3 & 1 & \\
\hline Time until fit for discharge (d) & $6(5-10)$ & $6(5-9)$ & .5597 \\
\hline Censored & 10 & 7 & \\
\hline Time to independent mobilization (d) & $4(3-7)$ & $4(3-6)$ & .5819 \\
\hline Censored & 8 & 7 & \\
\hline Time to mediastinal drain removal (h) & $26.1(20.6-53.3)$ & $22.5(19.4-37.8)$ & .0157 \\
\hline Censored & 2 & 2 & \\
\hline Time to extubation (h) & $9.2(7.8-12.1)$ & $8.3(6.8-11.7)$ & .5488 \\
\hline Censored & 1 & 1 & \\
\hline Theatre time (min) & $191(172-225)$ & $176(152-203)$ & $<.0001$ \\
\hline Censored & 0 & 0 & \\
\hline CPB time (min) & $80(70-95)$ & $66(52-85)$ & $<.0001$ \\
\hline Censored & 0 & 0 & \\
\hline Cross-clamp time (min) & $65(53-76)$ & $49(39-64)$ & $<.0001$ \\
\hline Censored & 0 & 0 & \\
\hline Surgery duration (min) & $163(139-190)$ & 149 (114-167) & $<.0001$ \\
\hline Censored & 3 & 4 & \\
\hline
\end{tabular}

(including superficial and deep infections) were more common in the FS group (13 vs 4 in the MS group; OR, $0.312 ; 95 \%$ CI, 0.097-1.005; $P=.0511)$. Deep sternal wound infection developed in $1 \mathrm{MS}$ recipient and $1 \mathrm{FS}$ recipient, neither of whom required plastic surgical repair.
Economic analyses are summarized in Table 3 and the cost-effectiveness planes depicting cost-effectiveness between MS and FS are shown in Figure 4. There was additional cost for MS relative to FS (£1714 per patient; $P=.0765)$ in the first year following surgery. Patients in

TABLE 3. Costs, QALYs, and cost-effectiveness

\begin{tabular}{|c|c|c|}
\hline \multirow[b]{2}{*}{ Cost and QALYs (with imputation) } & \multicolumn{2}{|c|}{ Cost per patient, $£$, mean (SD) } \\
\hline & FS $(\mathbf{n}=118)$ & MS $(n=104)$ \\
\hline \multicolumn{3}{|l|}{ Primary admission costs } \\
\hline Theatre use & $3824(1243)$ & $4422(2053)$ \\
\hline Additional surgical items & $16.52(0.0)$ & $52.0(0.0)$ \\
\hline Critical care (ITU) & $1834(3023)$ & $2934(5030)$ \\
\hline Cardiac ward & $2744(1664)$ & $2676(1500)$ \\
\hline Physical and occupational therapy & $77(55)$ & $78(68)$ \\
\hline Rehabilitation & $384(1878)$ & $263(1621)$ \\
\hline Acute hospital & 347 (1919) & $298(1971)$ \\
\hline Subtotal cost & $9226(6511)$ & $10,724(8850)$ \\
\hline \multicolumn{3}{|l|}{ Post primary admission costs to $12 \mathrm{mo}$} \\
\hline Hospital readmission & $418(1475)$ & $575(1863)$ \\
\hline Follow-up tests & $224(258)$ & $282(279)$ \\
\hline Follow-up health care visits & $373(359)$ & $311(263)$ \\
\hline Subtotal cost & 1015 (1778) & $1168(2079)$ \\
\hline Drugs & $379(548)$ & $441(977)$ \\
\hline Total cost over $12 \mathrm{mo}$ & $10,620(7624)$ & $12,333(9864)$ \\
\hline \multicolumn{3}{|c|}{ Incremental cost-effectiveness (probabilistic analysis with baseline adjustment)* } \\
\hline Incremental cost at 12 mo (MS-FS) & & $2154.0(\mathrm{SE} 36)$ \\
\hline Incremental EQ-5D-3L QALYs (MS-FS) & & $-0.0122($ SE 0.0008$)$ \\
\hline ICER & & MS dominated by FS \\
\hline NMB (at WTP $£ 20,000 / Q A L Y$ ) & & $-£ 2397$ \\
\hline NMB (at WTP $£ 30,000 / Q A L Y$ ) & & $-£ 2519$ \\
\hline
\end{tabular}

$O A L Y$, Quality-adjusted life-year; $S D$, standard deviation; $F S$, full median sternotomy; $M S$, mini-sternotomy; $I T U$, intensive therapy unit; $S E$, standard error; $I C E R$, incremental cost-effectiveness ratio; $N M B$, net monetary benefit; $W T P$, willingness to pay. *Incremental costs and effects estimated using SUR, adjusting for baseline differences. 

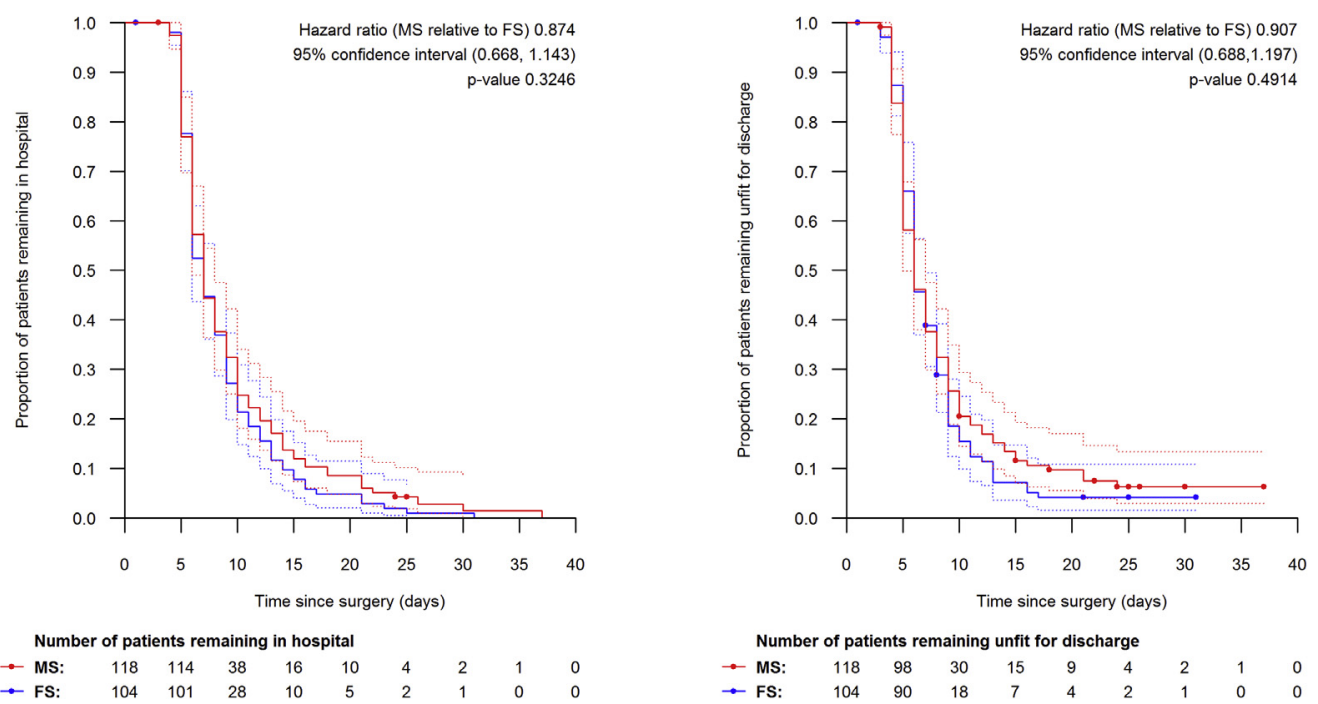

FIGURE 2. Kaplan-Meier curves for primary endpoints. Points indicate censoring, and dashed lines represent $95 \%$ confidence intervals. $M S$, Mini-sternotomy; FS, full median sternotomy.

the MS group had (nonsignificant) better EQ-5D-based QALYs (0.03 per patient; $P=.1509)$. The incremental cost per QALY gained was £61,379, but after adjusting for baseline characteristics, MS had higher costs and lower QALYs (ie, was dominated). In deterministic and probabilistic sensitivity analyses, MS was either dominated or had a very large cost per QALY, except for the complete case analysis (Tables E11 and E12).

\section{DISCUSSION}

The NHS is a free-for-patient at point-of-delivery health care system. Apart from good recovery, hospital discharge of a significant proportion of elderly patients depends on the timely availability of social care services in the community. The Mini-Stern trial is the first reported RCT

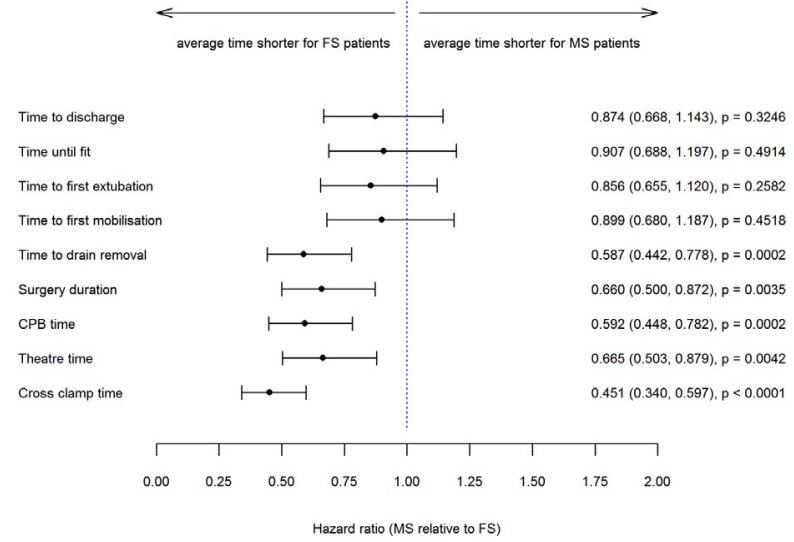

FIGURE 3. Forest plot of hazard ratios and $95 \%$ confidence intervals from Cox models. FS, Full median sternotomy; $M S$, mini-sternotomy; $C P B$, cardiopulmonary bypass. comparing FS and MS for isolated AVR performed in a cohort of NHS patients.

In this prospective, pragmatic, open-label RCT, MS did not reduce the total duration of hospital stay after AVR. Because hospital discharge is sometimes delayed due to social factors, we included the time to fitness for discharge as a second primary endpoint. This was also not reduced by MS. These endpoints were recorded by physiotherapists based on a common discharge protocol with specific clinical milestones to achieve, thereby excluding physician-induced bias.

In this study, operation, total theatre, aortic cross-clamp, and CPB times were significantly prolonged with MS. This

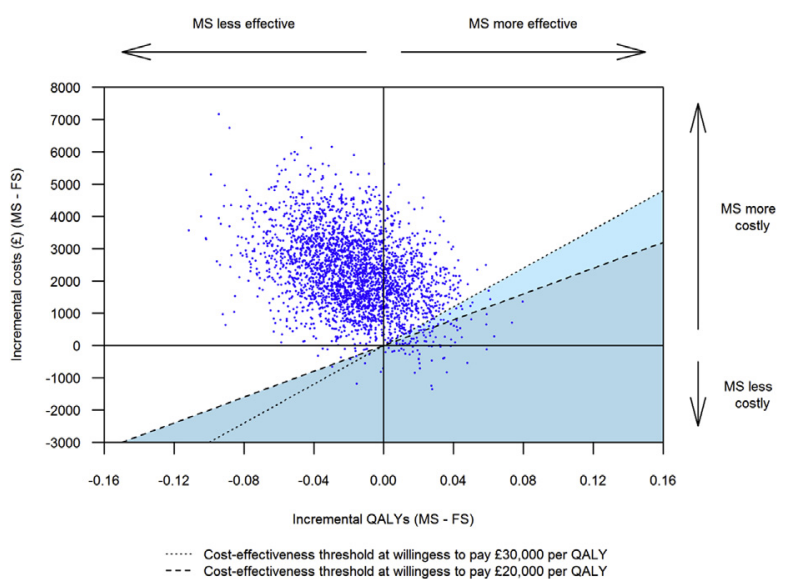

FIGURE 4. Cost-effectiveness planes. The proportion of points below each threshold gives the probability that MS is more cost-effective than FS. This probability is $3.7 \%$ for willingness to pay $£ 20,000$ per QALY and $5.1 \%$ for willingness to pay $£ 30,000$ per QALY. MS, Ministernotomy; $F S$, full median sternotomy; $Q A L Y$, quality-adjusted life-year. 
was expected, because in general, minimal access valve operations take longer. ${ }^{5,9}$ This would be justifiable if MS was associated with faster recovery, shorter postoperative stay, reduced cost of treatment, or, most importantly, a significant reduction in adverse events and hence superior patient safety. In this RCT, MS did not achieve these benefits, and thus we feel that the prolonged operation, total theatre, cross-clamp, and CPB times do not justify performing AVR through MS.

Two previous meta-analyses ${ }^{11,12}$ concluded that mAVR approaches are superior in certain aspects of postoperative recovery. However, both included studies on a mini-thoracotomy approach for AVR, and thus any inferences drawn cannot be extrapolated to MS. A retrospective propensity-matched analysis of data from a United Kingdom national database concluded that MS is safe and comparable to conventional AVR. ${ }^{14}$ The authors found that MS resulted in a shorter postoperative hospital stay, in disagreement with our findings. However, a propensity-matched study can suffer from selection bias if its matching algorithm produces treatment groups that are unbalanced in some unobserved characteristics. A recent retrospective study demonstrated the safety of right thoracotomy minimally invasive isolated and concomitant AVR in patients of all age groups. ${ }^{25}$ Because randomization balances study groups in known and unknown characteristics, results of the Mini-Stern trial should be more reliable than the findings of nonrandomized studies.

Previous studies investigating cost-effectiveness provided unclear conclusions. A report analyzing registry data from patients who underwent isolated primary $\mathrm{AVR}^{26}$ reported lower hospital costs with AVR performed through a right anterior thoracotomy compared with sternotomy-based approaches, with no significant differences in outcomes. The main reasons for the lower costs were earlier hospital discharge and reduced use of blood products. Ghanta et $\mathrm{al}^{27}$ noted that exclusion of rehabilitation costs could alter this finding. A review by Glauber et al, ${ }^{13}$ based on uncontrolled studies, noted that the higher cost of instruments and devices in mAVR could be offset by economic advantage gained by shorter hospital stays and lower complication rates. The Mini-Stern trial assessed cost-effectiveness using a range of sensitivity analyses, but only the complete case analysis showed MS to be cost-effective, suggesting lower costs but slightly worse outcomes with MS. However, this analysis used a potentially unrepresentative sample of just 90 patients, and was restricted to the first year following operation, with no long-term analysis beyond 1 year.

This RCT is robust with many merits, including on-table randomization, comprehensive and independent outcome assessment without physician bias, longer-term clinical assessment, HRQoL analysis, and economic analysis. There are some limitations, however. Although we report on secondary endpoints, this trial was powered to address only the primary endpoint. A total of 14 patients $(12 \%)$ allocated to MS received FS, another possible limitation. However, only 6 patients $(5 \%)$ had true conversion after an attempted MS, whereas 8 patients $(6.7 \%)$ went on to FS for safety reasons. Although this RCT was conducted in only 2 centers, thereby limiting generalizability, recruitment by 8 surgeons improved the generalizability. A total of 1024 patients were screened to recruit 222 patients $(21.7 \%)$. Although this suggests potential selection bias, only 125 eligible patients $(12.2 \%)$ failed recruitment, whereas the remaining $667(65.1 \%)$ did not meet the inclusion criteria. Blinding was not practical, because sternotomy dressings were usually changed at 48 hours after surgery and patients became aware of the approach, which might have caused bias in self-reported outcomes. Missing "pain at rest" data were unlikely to be missing at random, and thus imputation might not have addressed all potential biases. Despite having 2 primary outcomes, we did not adjust for multiple testing; however, because neither showed a significant between-group difference, this would not have affected our conclusions.

\section{CONCLUSIONS}

In this study, MS for AVR was not associated with quicker recovery or earlier hospital discharge. MS resulted in longer operations, increased costs, and resulted in more SAEs than FS. Overall, this pragmatic RCT did not provide evidence that MS results in better clinical or quality of life outcomes, or that MS is cost-effective compared with FS in the first year after AVR.

\section{Conflict of Interest Statement}

Authors have nothing to disclose with regard to commercial support.

We thank Dr Matt Glover, Jacinta Nalpon, and Chelliah Paramasivam for their contributions to this study.

\section{References}

1. The Society for Cardiothoracic Surgery in Great Britain \& Ireland. Blue Book online. Available at: http://bluebook.scts.org/\#ActivityRates. Accessed July 21, 2018

2. Rosengart TK, Feldman T, Borger MA, Vassiliades TA Jr, Gillinov AM, Hoercher KJ, et al. Percutaneous and minimally invasive valve procedures: a scientific statement from the American Heart Association Council on Cardiovascular Surgery and Anesthesia, Council on Clinical Cardiology, Functional Genomics and Translational Biology Interdisciplinary Working Group, and Quality of Care and Outcomes Research Interdisciplinary Working Group. Circulation. 2008;117:1750-67.

3. Merk DR, Lehmann S, Holzhey DM, Dohmen P, Candolfi P, Misfeld M, et al. Minimal invasive aortic valve replacement surgery is associated with improved survival: a propensity-matched comparison. Eur J Cardiothorac Surg. 2015; 47:11-7; discussion 17

4. Furukawa N, Kuss O, Aboud A, Schönbrodt M, Renner A, Hakim Meibodi K, et al. Ministernotomy versus conventional sternotomy for aortic valve replacement: matched propensity score analysis of 808 patients. Eur J Cardiothorac Surg. 2014;46:221-6; discussion 226-7. 
5. Bonacchi M, Prifti E, Giunti G, Frati G, Sani G. Does ministernotomy improve postoperative outcome in aortic valve operation? A prospective randomized study. Ann Thorac Surg. 2002;73:460-5; discussion 465-6.

6. Moustafa MA, Abdelsamad AA, Zakaria G, Omarah MM. Minimal vs median sternotomy for aortic valve replacement. Asian Cardiovasc Thorac Ann. 2007; $15: 472-5$.

7. Sharony R, Grossi EA, Saunders PC, Schwartz CF, Ribakove GH, Culliford AT, et al. Minimally invasive aortic valve surgery in the elderly: a case-control study. Circulation. 2003;108(Suppl 1):II43-7.

8. Bakir I, Casselman FP, Wellens F, Jeanmart H, De Geest R, Degrieck I, et al Minimally invasive versus standard approach aortic valve replacement: a study in 506 patients. Ann Thorac Surg. 2006;81:1599-604.

9. Aris A, Cámara ML, Montiel J, Delgado LJ, Galán J, Litvan H. Ministernotomy versus median sternotomy for aortic valve replacement: a prospective, randomized study. Ann Thorac Surg. 1999;67:1583-7.

10. Dogan S, Dzemali O, Wimmer-Greinecker G, Derra P, Doss M, Khan MF, et al Minimally invasive versus conventional aortic valve replacement: a prospective randomized trial. J Heart Valve Dis. 2003;12:76-80.

11. Lim JY, Deo SV, Altarabsheh SE, Jung SH, Erwin PJ, Markowitz AH, et al. Conventional versus minimally invasive aortic valve replacement: pooled analysis of propensity-matched data. J Card Surg. 2015;30: 125-34.

12. Phan K, Xie A, Di Eusanio M, Yan TD. A meta-analysis of minimally invasive versus conventional sternotomy for aortic valve replacement. Ann Thorac Surg. 2014;98:1499-511.

13. Glauber M, Ferrarini M, Miceli A. Minimally invasive aortic valve surgery: state of the art and future directions. Ann Cardiothorac Surg. 2015;4:26-32.

14. Attia RQ, Hickey GL, Grant SW, Bridgewater B, Roxburgh JC, Kumar P, et al. Minimally invasive versus conventional aortic valve replacement: a propensity-matched study from the UK National Data. Innovations (Phila). 2016;11:15-23; discussion 23.

15. Dolan P, Gudex C, Kind P, Williams A. A social tariff for EuroQoL: results from a UK general population survey. Working Paper 138chedp, University of York, Centre for Health Economics; 1995.

16. Brazier JE, Harper R, Jones NM, O'Cathain A, Thomas KJ, Usherwood T, et al Validating the SF-36 health survey questionnaire: new outcome measure for primary care. BMJ. 1992;305:160-4.
17. Ware JE, Snow KK, Kosinski M, Gandek B. SF-36 Health Survey: Manual and Interpretation Guide. Boston, MA: The Health Institute, New England Medical Center; 1993.

18. Schulz KF, Altman DG, Moher D. CONSORT 2010 statement: updated guidelines for reporting parallel group randomised trials. BMJ. 2010;340:c332.

19. Joint Formulary Committee. British National Formulary (BNF). Available at: https://www.bnf.org/. Accessed July 21, 2018.

20. Department of Health and Social Care, Gov.UK. NHS reference costs 2014 to 2015. Available at: https://www.gov.uk/government/publications/nhs-referencecosts-2014-to-2015. Accessed July 21, 2018.

21. NHS Prescription Services Electronic Drug Tariff. Available at: https://www nhsbsa.nhs.uk/pharmacies-gp-practices-and-appliance-contractors/drug-tariff. Accessed July 21, 2018.

22. Curtis L, Burns A. Unit costs of health and social care, 2015. Personal Social Services Research Unit, University of Kent. Available at: https://www.pssru.ac. uk/project-pages/unit-costs/unit-costs-2015/. Accessed July 21, 2018.

23. Brazier J, Roberts J, Deverill M. The estimation of a preference-based measure of health from the SF-36. J Health Econ. 2002;21:271-92.

24. Faria R, Gomes M, Epstein D, White IR. A guide to handling missing dat in cost-effectiveness analysis conducted within randomised controlled trials Pharmacoeconomics. 2014:32:1157-70.

25. Lamelas J, Mawad M, Williams R, Weiss UK, Zhang Q, LaPietra A. Isolated and concomitant minimally invasive minithoracotomy aortic valve surgery. J Thorac Cardiovasc Surg. 2018;155:926-36.e2.

26. Rodriguez E, Malaisrie SC, Mehall JR, Moore M, Salemi A, Ailawadi G, et al. Right anterior thoracotomy aortic valve replacement is associated with less cost than sternotomy-based approaches: a multi-institution analysis of "real world" data. J Med Econ. 2014:17:846-52.

27. Ghanta RK, Lapar DJ, Kern JA, Kron IL, Speir AM, Fonner E Jr, et al. Minimally invasive aortic valve replacement provides equivalent outcomes at reduced cost compared with conventional aortic valve replacement: a real-world multi-institutional analysis. J Thorac Cardiovasc Surg. 2015;149:1060-5.

Key Words: aortic valve replacement, minimal access, health economics 


\section{APPENDIX E1. ECONOMIC EVALUATION}

This trial collected data on resource and health service use for each patient during their in-patient stay through to the end of follow-up at 1 year. The economic analysis compared the costs and quality of life impacts of full median sternotomy (FS) and mini-sternotomy (MS) and assessed the cost-effectiveness of MS as an alternative to FS.

The Methods section first presents the unit costs, resource use data and the methods used to aggregate resource use and utility data at a patient level. ${ }^{\mathrm{E} 1}$ The methods used to document and impute missing data follow. ${ }^{\mathrm{E} 2}$ The last part describes the construction of incremental cost-effectiveness ratios and representation of uncertainty.

Results are presented first for raw data (with and without imputation) for costs and quality-adjusted life-years (QALYs) separately, followed by estimations of costs and QALYs that account for baseline differences. The final section provides results of probabilistic and deterministic sensitivity analyses.

\section{METHODS \\ Unit Costs}

All resource use data collected formed part of the patient-specific case-report form. Trained research nurses extracted data for inpatient stays from individual patient records. Face-to-face interviews with patients by research nurses provided data for quality of life as well as health service use during follow-up.

Multiplying the unit costs by each unit of resource use and summing these resource costs across each patient's 12-month follow-up from the date of operation enabled aggregation of total cost per patient. Table E16 provides the unit costs used, with source of data. Where possible, national estimates of unit prices were used (eg, Personal Social Services Research Unit, ${ }^{\mathrm{E} 3}$ National Health Service ${ }^{\mathrm{E} 4}$ ), to increase generalizability.

All resources were used once by patients (eg, a general practitioner visit or specific test), with the exception of 2 capital items used during surgery; the horizontal saw and defibrillator handles, both acquired for MS. These costs were apportioned, using clinical opinion, to each patient assuming a lifespan of 20 years and that surgeons perform a total of 255 MSs over 5 years.

\section{Patient-Level Aggregation of Cost}

This section describes the aggregation of costs, by patient, for the inpatient stay, postdischarge follow-up to 12 months, and drug use.

Hospital stay. The time in the hospital from randomization to discharge was disaggregated into theatre time, critical care unit (CCU), stay and cardiac ward stay (Table E17). The total length of stay comprised the time spent in surgery (measured in minutes), in the CCU (measured in hours), and in the cardiac ward (measured in days). Theatre time included the duration of reoperations where applicable (several patients had up to 2 returns to the theatre), and corresponding CCU stays were added to the CCU hours. The total stay in the hospital, calculated using theatre time, critical care, and ward stay, was compared with a direct calculation of duration using date of operation and date of discharge, to validate the breakdown of patient stay. After discharge from hospital, the majority of patients were discharged to home, but some were referred to an acute hospital or rehabilitation center (short or long term) for more care, and the costs of this additional stay were included.
Postdischarge. Data on resource use after discharge and for up to 12 months postrandomization were collected at 6-week, 6-month, and 12-month follow-up visits, with resource use divided into 3 categories: hospital admissions, tests and health care visits. A total of 28 different health care resources were used and aggregated over the follow-up period. For example, if a patient reported 1 blood test from discharge to the 6-week follow-up, 2 blood tests between the 6-week and 6-month follow-ups, and none after that, resource use was costed as $£ 10.38(3 \times £ 3.46)$ postdischarge.

Drugs. Drug use was matched to a corresponding unit cost using the NHS Electronic Drug tariff ${ }^{\mathrm{E} 5}$ and British National Formulary ${ }^{\mathrm{E} 6}$ to sum costs across drug type for each patient. Information on drugs administered during the primary admission was complete, with the total amount of each drug per patient checked against patient prescriptions. However, drug use postdischarge was self-reported, and it was not possible to verify or retrieve any further data on this over the follow-up period.

Health state utilities. These data were collected using EQ-5D-3L and SF-36 questionnaires. EQ-5D-3L responses were converted to utility values using the methods described by Dolan et al. ${ }^{\mathrm{E} 7}$ and to QALYs for the trial period using the area under the curve method. SF-36 data were mapped to SF-6D utility values based on the ScHARR (School of Health and Related Research, University of Sheffield) algorithm and were converted to QALY scores as described by Brazier et al. ${ }^{\mathrm{E} 8} \mathrm{~A}$ value of 0 was assigned from date of death.

\section{Missing Data}

The patterns of missing data for resource use and utilities were tested using Pearson $\chi^{2}$ goodness-of-fit and Wilcoxon rank-sum tests for being missing at random and completely at random using the following variables: age, sex, treatment, and health status at baseline (EQ-5D). The baseline characteristics assessed were not statistically significantly different between the 2 groups, and multiple imputations were used for economic analysis. Patients were assigned zero cost and zero utility value from point of death.

Hospital stay. For primary admission, there were a few item nonresponses for resource use data but no censored data. Complete information was available on all respondents except for 1 participant who withdrew from the trial after operation.

Postdischarge. The frequency of missing data for resource use after discharge in the 2 groups is provided in Table E18. Imputation models did not converge at month 12 , and resource use was aggregated over time; that is, imputation was carried out for the aggregate value for each item rather than at each time period. The proportion of missing values in the aggregated utility data ranged from $11 \%$ to $25 \%$ in resource use postdischarge (Table E18).

Drugs. Only drugs used from the time of randomization to the 12-month follow-up were accounted for (covering 3078 uses of 118 different drugs). Various assumptions (about quantity/dose and duration of administration) were used to minimize the degree of missing information on the drugs used. For example, when dosage or frequency of dose per day was missing, the mode of use among trial participants or, if not available, the British National Formulary dosage was used. Duration of medicinal use was calculated using start and stop dates for drugs used in primary admission and follow-up. However, when start/stop dates were missing, replies to a "yes/no" question on use of drugs at follow-up time points informed duration. For example, if a drug was taken during the inpatient stay and at 6-week, 6-month, and 12-month follow-ups, then the drug was said to be used for the entire 12-month trial period. However, further assumptions about duration of medication were used when data were less forthcoming; for example, drugs taken only at the 12-month follow-up, without a start date or stop date specified, were assumed to have been taken according to 
prescription every day for an average of 3 months (based on expert consultation). Fifty-eight records had insufficient information on usage for such personalized manual imputation, necessitating predictive mean matching (conditioned on patient ID and name of drug).

Health state utilities. EQ-5D-3L and SF-6D utility data were imputed at each follow-up as presented in Table E19, and the percentage of missing values ranged from $9 \%$ to $23 \%$. Further breakdown of missing data for resource use and health-related quality of life questionnaires, and imputation required for each variable, is provided in Table E19.

\section{Imputation}

Missing values were imputed conditional on sex, age, type of replacement valve used, risk classification measured using New York Heart Association functional classification and Canadian Cardiovascular Society grading of angina. To avoid loss in efficiency, missing values for resource use and utility values at different time points were replaced using multiple imputations by chained equations.

Chained predictive mean matching was used to replace missing data for resource use and quality of life variables, and a total of 20 imputed datasets were created, stratified by treatment group. The imputed resource use is summarized in Table E20. However, although probabilistic analysis was conducted using the bootstrap method, multiple imputation was carried out only once for each iteration, with a total of 1000 iterations to adequately retain between-imputation variance. The distribution of imputed values was visually checked for comparability with the observed data.

\section{Adjustment Method}

To account for differences in baseline utility values, as well as skewness, censoring, and confounding in cost data, linear regression models were used to provide adjusted estimates of mean values. Control variables used were age, sex, valve, EQ-5D-3L baseline value, and treatment arm. The type of valve used for replacement was also controlled for, because it was used as a stratification factor in the randomization.

\section{Incremental Cost-Effectiveness Analysis and \\ Sensitivity Analyses}

Differences in estimated costs and EQ-5D QALYs between trial arms, using raw data with imputation, were tested using a 2-sample $t$ test with equal variances. Incremental cost-effectiveness ratios were also constructed using adjusted mean estimates of costs and QALYs using "seemingly unrelated regression," to account for correlation between costs and effects at the patient level. This regression technique relies on the multivariate normality of the group-specific mean costs and QALYs and is valid where the individual costs and QALYs are skewed. ${ }^{\text {E9 }}$

Probabilistic sensitivity analysis was used to characterize the uncertainty of input parameters, and a bootstrap approach (with 1000 bootstrapped samples) was applied to estimate the precision of results. The probability that MS is cost-effective compared with FS is presented at varying willingness to pay (WTP) threshold values, using a costeffectiveness acceptability curve and incremental net monetary benefit.

Deterministic sensitivity analyses and scenario analysis were used to explore the robustness of cost-effectiveness results that adopted different methodological approaches or assumptions (Table E21). Baseline characteristics were assessed using the $\chi^{2}$ and rank-sum tests, to assess whether patients included in the complete-case analysis were different from those outside the complete-case analysis.

\section{RESULTS}

The comparison of mean costs per patient up to 1 year, using raw data with imputation, shows that MS cost $£ 1714$ more than FS, although this was not statistically significant
(Table E22). The higher costs resulted from longer surgery time, additional equipment, and longer time in critical care. EQ-5D QALYs were very slightly higher in the MS arm compared with the FS arm (difference, 0.0279), but this was not statistically significant (Table E23), and there was no statistically significant difference in SF-6D QALYs either. Figures E2 and E3 illustrate the distribution of total costs and QALYs across the patients in the trial.

Table E24 summarizes the comparison of costs and QALYs. The additional cost of gaining an additional QALY using MS rather than FS when imputed using the PMM method is $£ 61,379$, and the net monetary loss at a WTP of $£ 20,000$ is $£ 1155$.

Seemingly unrelated regression analysis of costs and QALYs, adjusted for baseline characteristics, showed that in terms of QALYS, MS was not statistically significantly different from FS. Table E25 also shows that the coefficient for cost was positive, indicating that MS was more costly than FS, and that this difference was statistically significant. Thus, MS is dominated by FS. The cost-effectiveness plane for the analysis is illustrated in Figure E4.

The probabilistic sensitivity analysis shows that at a WTP per QALY of $£ 20,000$, there is a $3.7 \%$ likelihood that MS is cost-effective compared with FS, and that this likelihood rises to $5.1 \%$ at a WTP of $£ 30,000 / \mathrm{QALY}$ (Figure E5). The net monetary benefit of MS is negative across all WTP threshold values (Figure E6).

Deterministic sensitivity analyses showed that MS was either dominated or had a huge ICER (Table E26). The one exception to this was the complete-case analysis of cost-effectiveness, which found MS to be cost-effective. The intervention cost less but also had slightly worse outcomes in this sample size, which was limited to only 90 cases. The result indicates a saving of $£ 10,000$ for a loss of 1 QALY. The sample was not representative of those with missing data and included a larger proportion of females than the sample outside the complete-case analysis cost-effectiveness sample. The sensitivity analyses conducted using probabilistic sensitivity analysis consistently found FS to be a superior intervention to MS (Table E27). The cost-effectiveness planes for the sensitivity analyses are illustrated in Figure E7.

\section{E-References}

E1. Lovibond K, Jowett S, Barton P, Caulfield M, Heneghan C, Hobbs FD, et al Cost-effectiveness of options for the diagnosis of high blood pressure in primary care: a modelling study. Lancet. 2011;378:1219-30.

E2. Auguste P, Barton P, Hyde C, Roberts TE. An economic evaluation of positron emission tomography (PET) and positron emission tomography/computed tomography (PET/CT) for the diagnosis of breast cancer recurrence. Health Technol Assess. 2011;15:1-54.

E3. Personal Social Services Research Unit. Unit costs of health and social care, 2015. Available at: http://www.pssru.ac.uk. Accessed July 1, 2016. 
E4. Department of Health. NHS Reference costs, 2014/15. Available at: https://www.gov. uk/government/publications/nhs-reference-costs-2014-to-2015. Accessed July 1, 2016.

E5. National Health Service Electronic Drug Tariff. Available at: http:// www.nhsbsa.nhs.uk/PrescriptionServices/4940.aspx. Accessed July 1, 2016.

E6. British National Formulary, 2016. Available at: https://www.nice.org.uk/about what-we-do/evidence-services/british-national-formulary. Accessed July 1, 2016
E7. Dolan P, Gudex C, Kind P, Williams A. A social tariff for EuroQol: results from a UK general population survey. Working paper 138. University of York Center for Health Economics, 1995:1-24.

E8. Brazier J, Roberts J, Deverill M. The estimation of a preference-based measure of health from the SF-36. J Health Econ. 2002;21:271-92.

E9. Faria R, Gomes M, Epstein D, White IR. A guide to handling missing data in cost-effectiveness analysis conducted within randomised controlled trials. Pharmacoeconomics. 2014;32:1157-70. 


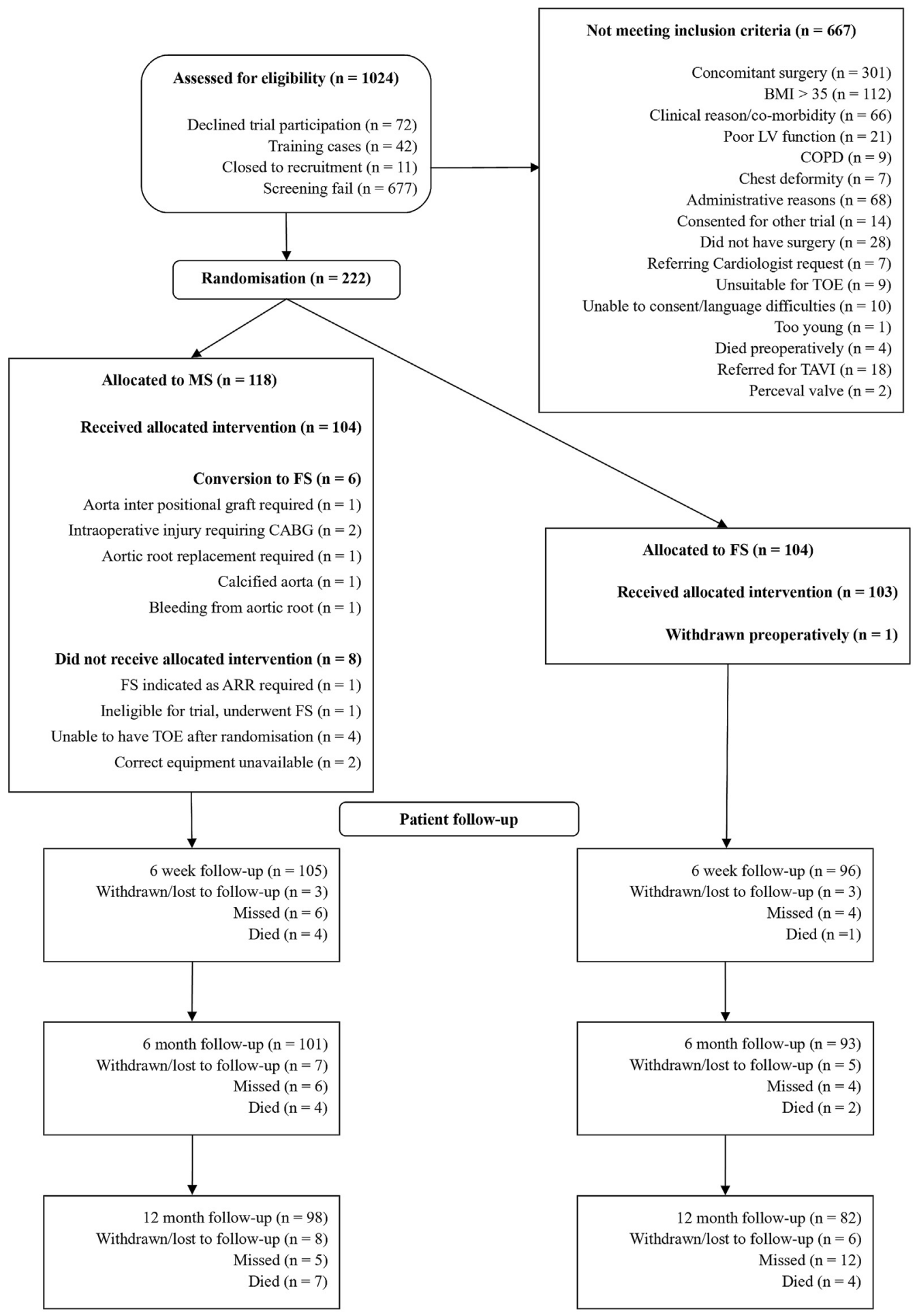

FIGURE E1. MiniStern Trial. CONSORT flow diagram. BMI, Body mass index; $L V$, left ventricular; $C O P D$, chronic obstructive pulmonary/airway disease; TOE, transesophageal echocardiography; TAVI, transcutaneous aortic valve implantation; $M S$, mini-sternotomy; $F S$, full median sternotomy; $C A B G$, coronary artery bypass grafting; $A R R$, aortic root replacement. 


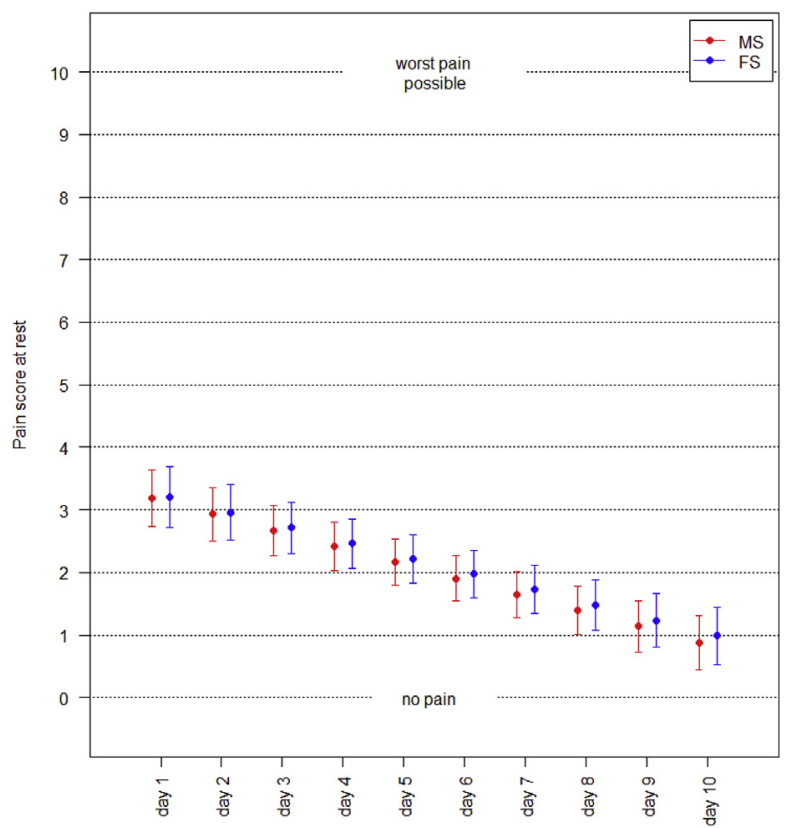

FIGURE E2. Forest plots of mean pain scores for the first 10 days following surgery, with $95 \%$ confidence intervals. Means on each day were adjusted for sex and valve type and were estimated from the complete-case analysis. MS, Mini-sternotomy; FS, full median sternotomy.

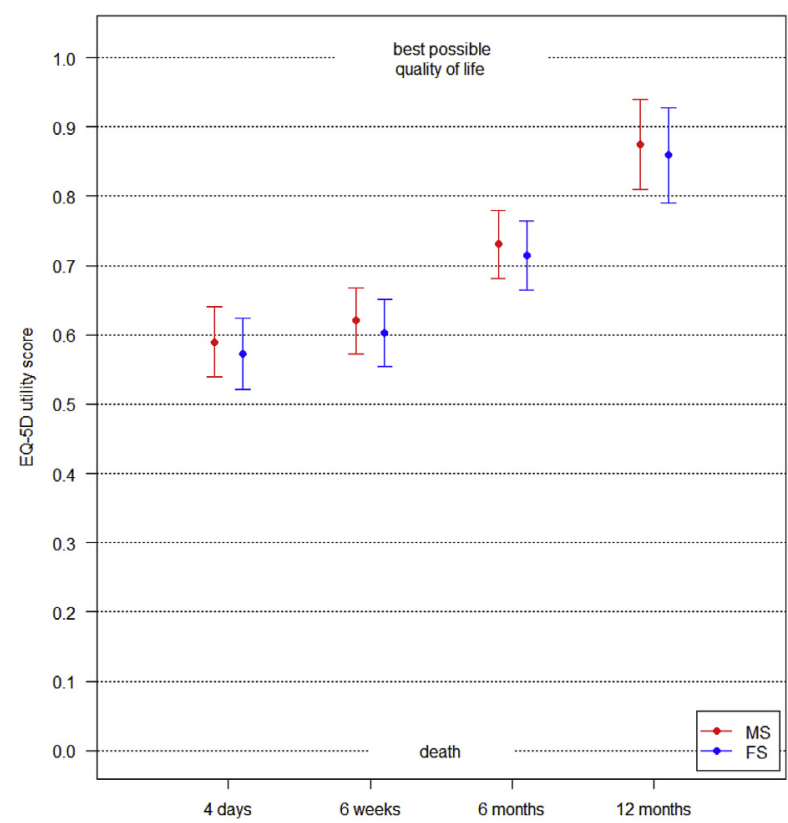

FIGURE E3. Forest plot of mean EQ-5D scores at each follow-up time, with $95 \%$ confidence intervals. Means at each follow-up time were adjusted for baseline EQ-5D, sex, and valve type and were estimated from the complete-case analysis. $M S$, Mini-sternotomy; $F S$, full median sternotomy. 

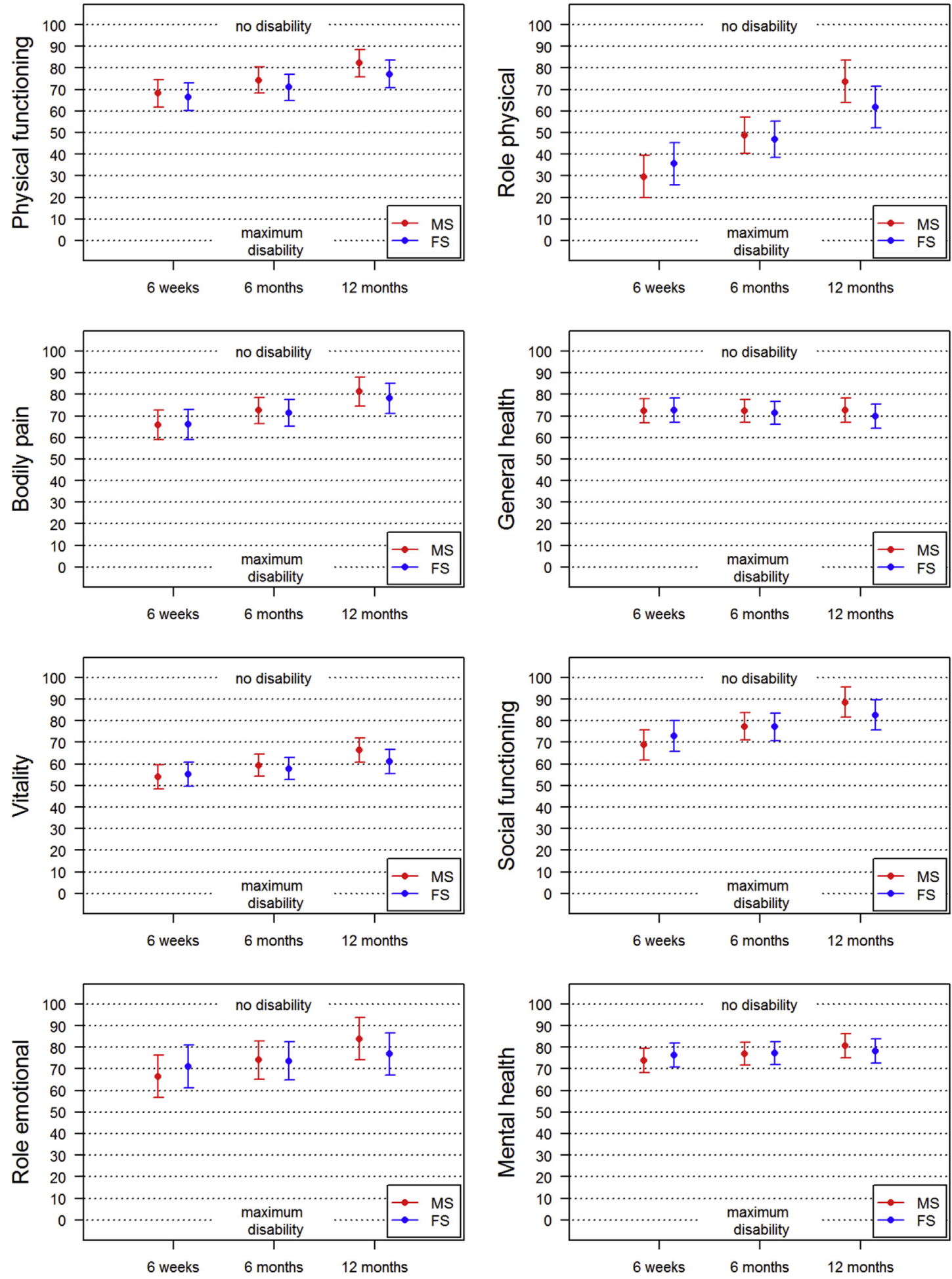

FIGURE E4. Forest plot of mean SF-36 domain scores at each follow-up time, with $95 \%$ confidence intervals. Means at each follow-up time were adjusted for baseline domain score, sex, and valve type and were estimated from the complete-case analysis. A score of 100 represents no disability, and a score of 0 represents maximum disability. $M S$, Mini-sternotomy; $F S$, full median sternotomy. 


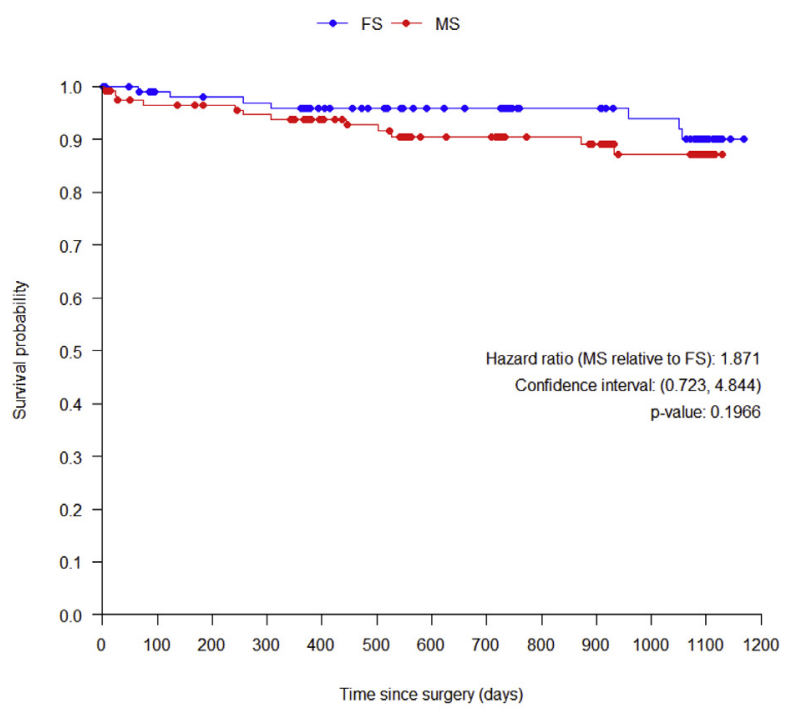

Number at risk

$\begin{array}{llcccccccccccc}\text { MS: } & 118 & 109 & 106 & 103 & 91 & 86 & 70 & 69 & 63 & 60 & 46 & 22 & 0 \\ \text { FS: } & 104 & 96 & 91 & 90 & 82 & 77 & 67 & 65 & 58 & 58 & 49 & 16 & 0\end{array}$

FIGURE E5. Kaplan-Meier curves for time to death by any cause. Patients are grouped by the treatment allocated to them. Patients with no fatal events recorded were censored at the last time known to be alive. Times of censoring are indicated by points on the curves. $M S$, Mini-sternotomy; $F S$, full median sternotomy.

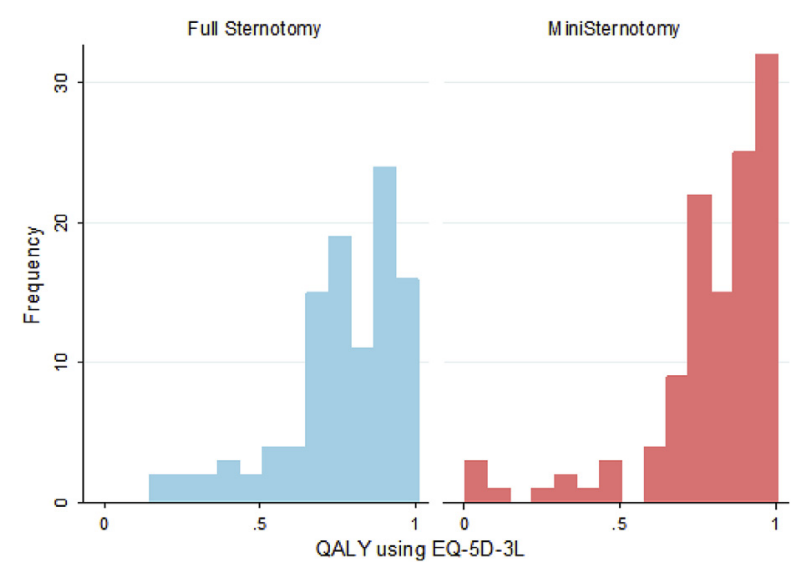

FIGURE E7. Distribution of quality-adjusted life-years. $Q A L Y$, Qualityadjusted life-year.

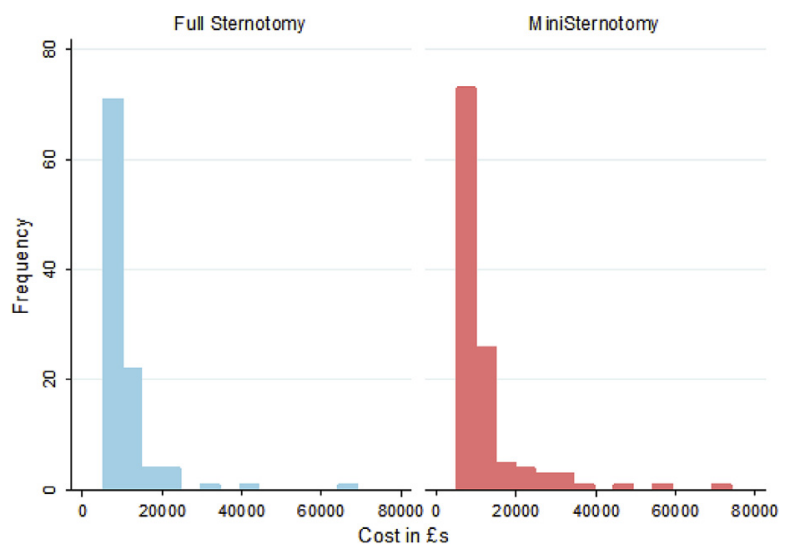

FIGURE E6. Distribution of total cost 


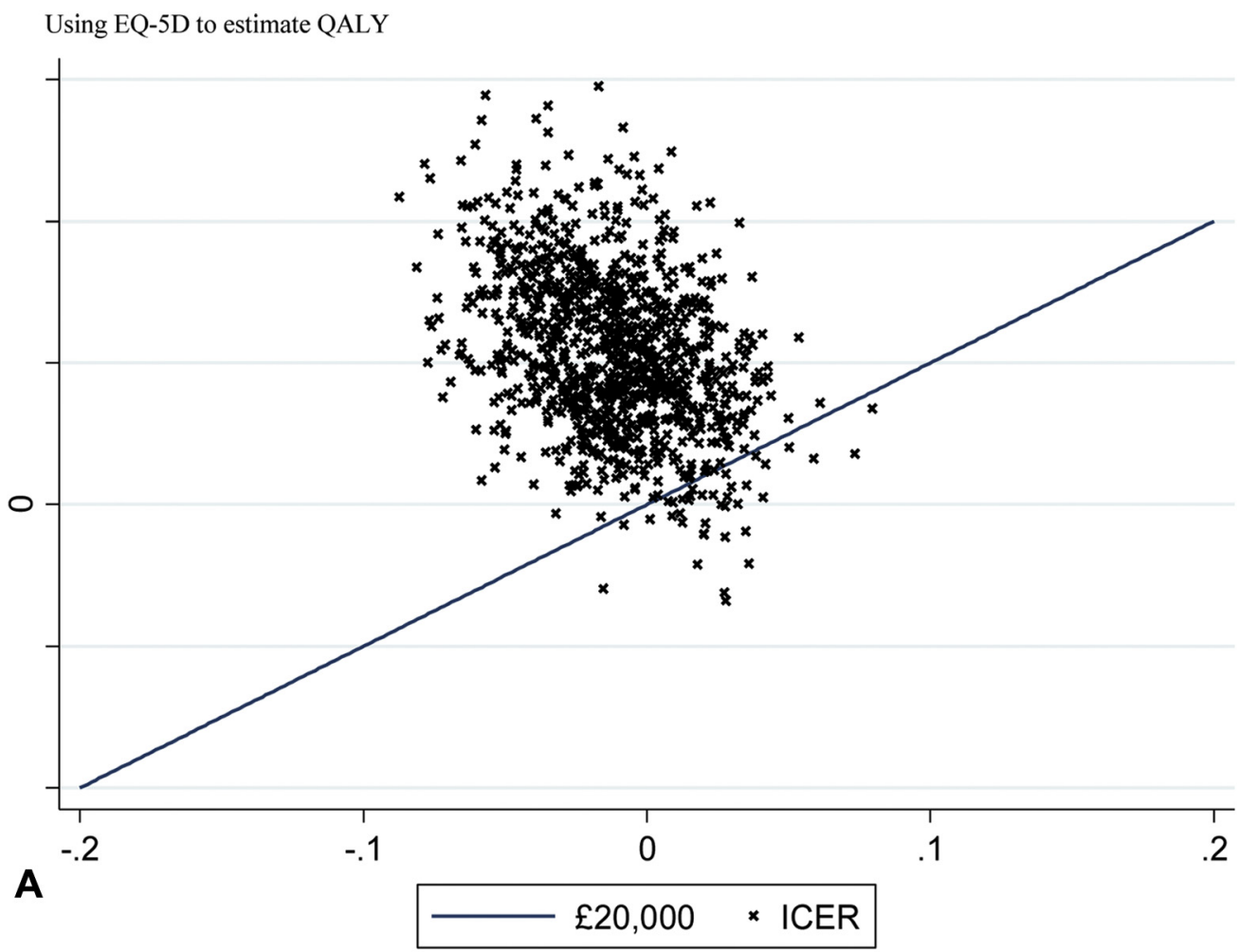

Using SF-36 to estimate QALY

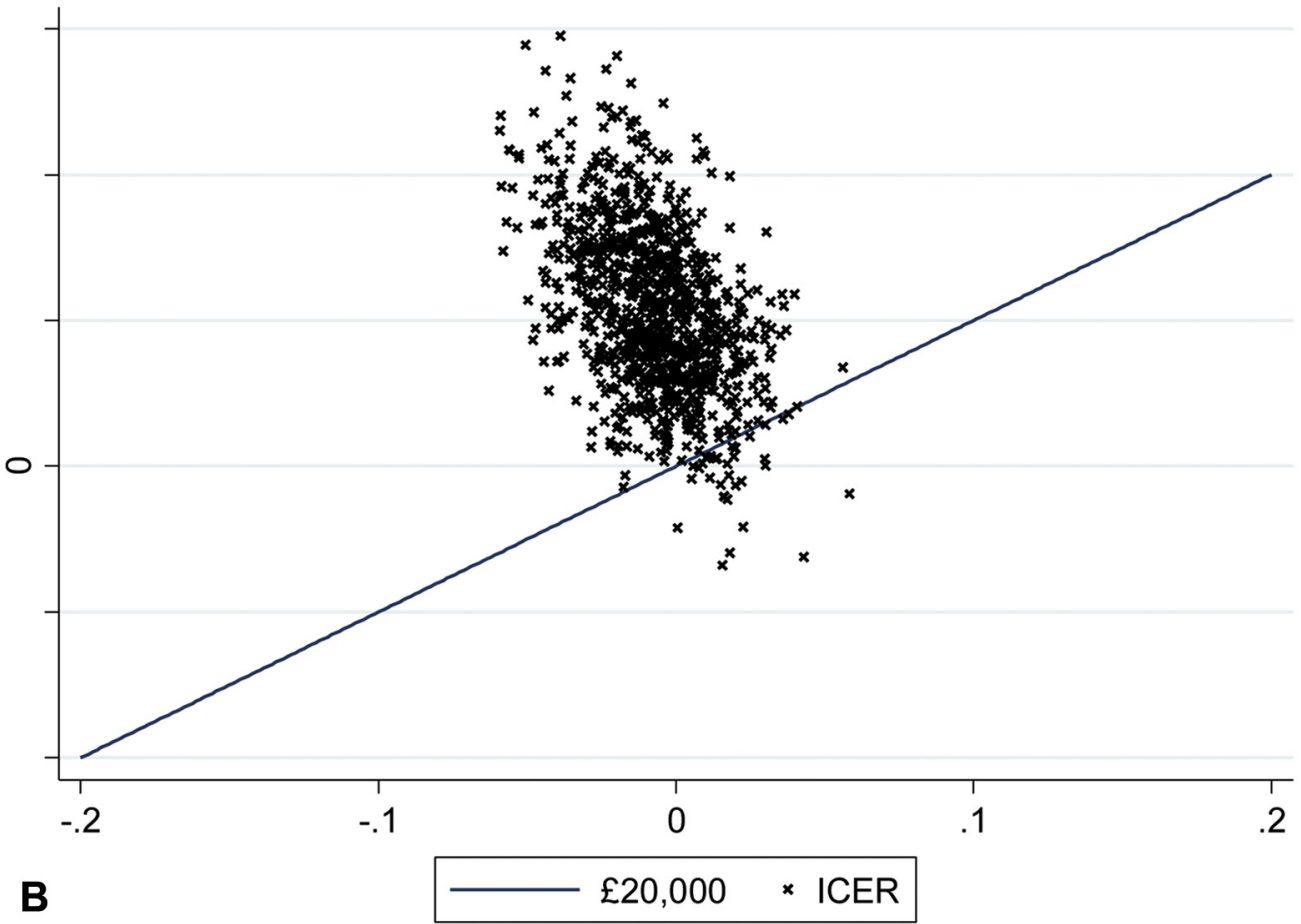

FIGURE E8. Cost-effectiveness plane, using the difference mini-sternotomy $(M S)$ - full sternotomy ( $F S)$, adjusted for baseline. A, Using EQ-5D to estimate quality-adjusted life-years $(Q A L Y S)$. B, Using SF-36 to estimate QALYs. ICER, Incremental cost-effectiveness ratio. 


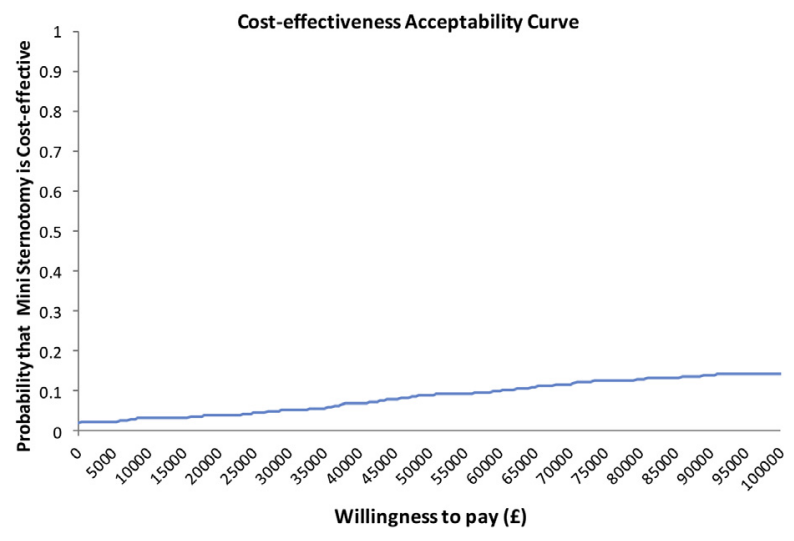

FIGURE E9. Cost-effectiveness acceptability curve (EQ-5D).

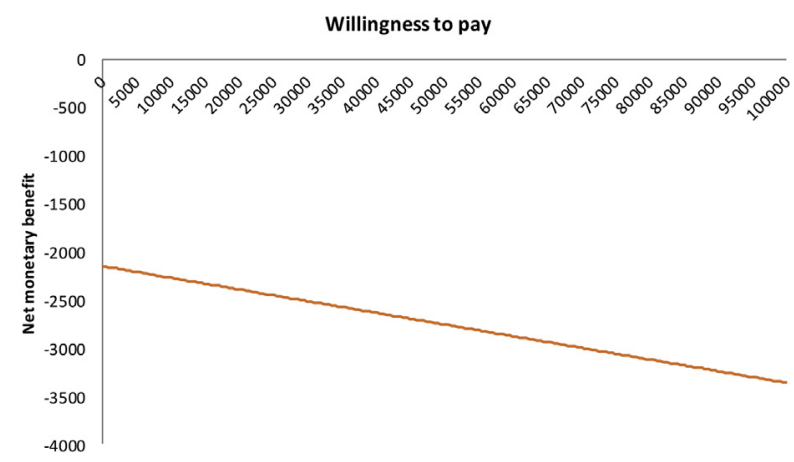

FIGURE E10. Net monetary benefit, controlling for baseline characteristics and missing data. 

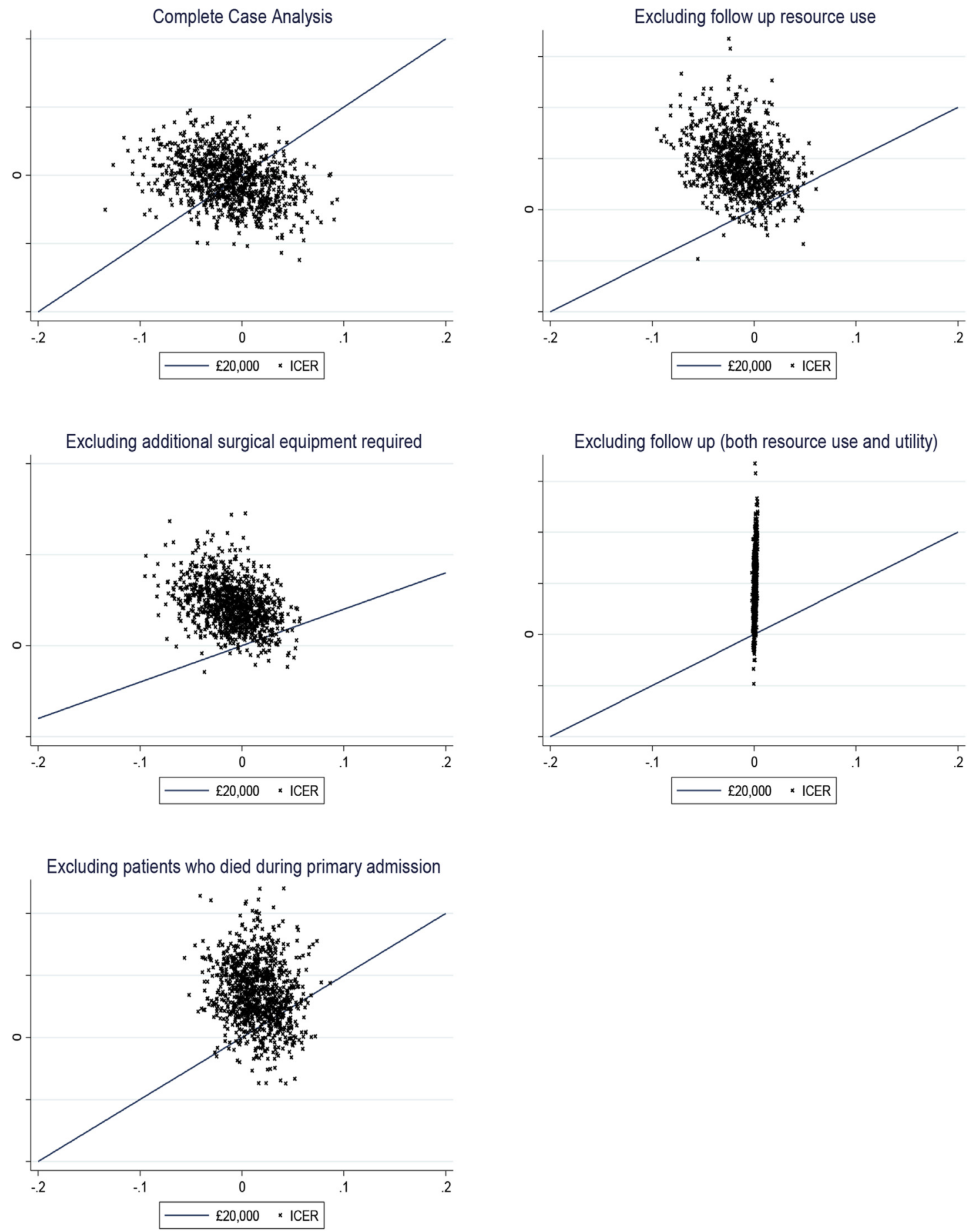

FIGURE E11. Sensitivity analyses using the difference mini-sternotomy (MS) - full sternotomy (FS), adjusted for baseline. ICER, Incremental cost-effectiveness ratio. 
TABLE E1. Patients who underwent redo sternotomy, crossed over from mini sternotomy to full sternotomy, or were randomized but deemed ineligible

\begin{tabular}{|c|c|c|c|c|}
\hline Operation & $\begin{array}{l}\text { Allocated } \\
\text { treatment }\end{array}$ & Description & $\begin{array}{l}\text { Per-protocol } \\
\text { population }\end{array}$ & $\begin{array}{c}\text { Safety } \\
\text { population }\end{array}$ \\
\hline \multirow[t]{8}{*}{ Redos } & FS & Return to theatre for ventricular septal defect closure and redo AVR & As FS & As FS \\
\hline & FS & $\begin{array}{l}\text { Return to theatre for tamponade and cardiac arrest; redo sternotomy for } \\
\text { tamponade }\end{array}$ & As FS & As FS \\
\hline & MS & Return to theatre for tamponade MA bleed; conversion to FS & As MS & As MS \\
\hline & MS & Return to theatre for bleeding; redo FS & As MS & As MS \\
\hline & MS & $\begin{array}{l}\text { Return to theatre for tamponade; evacuation of clot/pericardial effusion; } \\
\text { conversion to FS }\end{array}$ & As MS & As MS \\
\hline & MS & $\begin{array}{l}\text { Return to theatre for cardiac arrest and tamponade; emergency resternotomy } \\
\text { (FS), tamponade, and aortotomy repair }\end{array}$ & As MS & As MS \\
\hline & MS & $\begin{array}{l}\text { Return to theatre for pericardial collection and early tamponade; PEA arrest; } \\
\text { reexploration on bypass; completion of FS }\end{array}$ & As MS & As MS \\
\hline & MS & $\begin{array}{l}\text { Second return to theatre, attempted weaning of ECMO and placement of } \\
\text { RVAD; removal of blood clot; redo sternotomy }\end{array}$ & As MS & As MS \\
\hline \multirow[t]{13}{*}{ Crossovers } & MS & Aortic root replacement required, FS indicated & Excluded & As FS \\
\hline & MS & FS indicated as unable to perform TOE & Excluded & As FS \\
\hline & MS & Aorta interposition graft required & Excluded & As MS \\
\hline & MS & FS indicated as unable to have TOE & Excluded & As FS \\
\hline & MS & CABG required due to intraoperative injury & Excluded & As MS \\
\hline & MS & $\mathrm{CABG}$ required due to intraoperative injury & Excluded & As MS \\
\hline & MS & FS indicated as unable to perform TOE & Excluded & As FS \\
\hline & MS & Required aortic root replacement, conversion to FS & Excluded & As MS \\
\hline & MS & Patient randomized too early; unable to insert TOE probe & Excluded & As FS \\
\hline & MS & Did not have correct equipment in theatre & Excluded & As FS \\
\hline & MS & Mini-sternotomy equipment not available & Excluded & As FS \\
\hline & MS & Bleeding & Excluded & As MS \\
\hline & MS & Patient had calcified aorta; nowhere to cannulate safely & Excluded & \\
\hline \multirow[t]{3}{*}{ Ineligible } & FS & $\begin{array}{l}\text { Withdrawn from trial by surgeon preoperatively (but postrandomization); } \\
\text { AVR and myectomy required }\end{array}$ & Excluded & Excluded \\
\hline & FS & Poor-quality baseline echocardiogram, with no assessment of LV function & Excluded & As FS \\
\hline & MS & $\begin{array}{l}\text { Surgeon had not checked echocardiography report until after } \\
\text { randomization; FS performed }\end{array}$ & Excluded & As FS \\
\hline
\end{tabular}

$F S$, Full sternotomy; $A V R$, aortic valve replacement; $M S$, mini-sternotomy; $M A$, internal mammary artery; $P E A$, pulseless electrical activity; $E C M O$, extracorporeal membrane oxygenation; $R V A D$, right ventricular assist device; $T O E$, transesophageal echocardiography; $C A B G$, coronary artery bypass grafting; $L V$, left ventricular. 
TABLE E2. Additional summaries of in-hospital endpoints, KaplanMeier estimates

\begin{tabular}{|c|c|c|}
\hline Endpoint & $\begin{array}{l}\text { Mini-sternotomy } \\
\qquad(\mathbf{n}=\mathbf{1 1 8})\end{array}$ & $\begin{array}{l}\text { Full sternotomy } \\
\quad(\mathbf{n}=\mathbf{1 0 4})\end{array}$ \\
\hline \multicolumn{3}{|l|}{ Time to discharge (d) } \\
\hline Mean (SE) & $9.5(0.6)$ & $8.6(0.5)$ \\
\hline Median $(95 \%$ CI $)$ & $7(6-8)$ & $7(6-8)$ \\
\hline \multicolumn{3}{|c|}{ Time to fit for discharge (d) } \\
\hline Mean (SE) & $8.5(0.5) *$ & $7.5(0.3)^{*}$ \\
\hline Median $(95 \% \mathrm{CI})$ & $6(5-7)$ & $6(6-7)$ \\
\hline \multicolumn{3}{|c|}{ Time to first mobilization (d) } \\
\hline Mean (SE) & $5.7(0.5)^{*}$ & $4.9(0.3)^{*}$ \\
\hline Median $(95 \%$ CI $)$ & $4(3-4)$ & $4(-) \dagger$ \\
\hline \multicolumn{3}{|c|}{$\begin{array}{l}\text { Time to mediastinal drain } \\
\text { removal (h) }\end{array}$} \\
\hline Mean (SE) & $48.1(4.8)^{*}$ & $30.0(1.7)$ \\
\hline Median $(95 \% \mathrm{CI})$ & $26.1(22.8-42.6)$ & $22.5(22.0-22.9)$ \\
\hline \multicolumn{3}{|c|}{ Time to first extubation (h) } \\
\hline Mean (SE) & $13.1(1.7)^{*}$ & $10.5(0.7)$ \\
\hline Median $(95 \%$ CI $)$ & $9.2(8.7-9.9)$ & $8.3(8.0-9.2)$ \\
\hline \multicolumn{3}{|c|}{$\begin{array}{l}\text { The table presents the Kaplan-Meier estimates of in-hospital endpoints. Censoring of } \\
\text { longest time to event for some endpoints led to underestimation of means and } \\
\text { standard errors (highlighted with asterisks). A confidence interval for median time } \\
\text { to mobilization could not be estimated. Table E5 shows the number of pain scores } \\
\text { obtained on each of the } 10 \text { days following surgery. The denominator used for each } \\
\text { percentage is the number of patients known to be alive and in hospital on the given } \\
\text { day. } S E \text {, Standard error; } C I \text {, confidence interval. *Censoring of longest time to event } \\
\text { for some endpoints led to underestimation of means and SEs. } \dagger \text { A CI for median time } \\
\text { to mobilization could not be estimated. }\end{array}$} \\
\hline
\end{tabular}


TABLE E3. Additional summaries of operative endpoints

\begin{tabular}{|c|c|c|}
\hline Endpoint & Mini-sternotomy $(\mathrm{n}=118)$ & Full sternotomy $(n=104)$ \\
\hline \multicolumn{3}{|l|}{ Theatre time (min) } \\
\hline Mean (SE) & $201.2(3.9)$ & $181.0(4.6)$ \\
\hline Median $(95 \% \mathrm{CI})$ & $191(187-205)$ & $176(170-180)$ \\
\hline \multicolumn{3}{|l|}{ CPB time (min) } \\
\hline Mean (SE) & $82.0(1.9)$ & $69.5(2.3)$ \\
\hline Median $(95 \% \mathrm{CI})$ & $80(77-86)$ & $66(59-74)$ \\
\hline \multicolumn{3}{|l|}{ Cross-clamp time (min) } \\
\hline Mean (SE) & $65.5(1.5)$ & $52.4(1.6)$ \\
\hline Median $(95 \% \mathrm{CI})$ & $65(61-69)$ & $49(45-53)$ \\
\hline \multicolumn{3}{|l|}{ Surgery duration $(\mathrm{min})$} \\
\hline Mean (SE) & $165.5(3.4)$ & $145.7(4.3)$ \\
\hline Median $(95 \% \mathrm{CI})$ & $163(155-172)$ & $148.5(134-153)$ \\
\hline \multicolumn{3}{|c|}{ Total theatre time, including repeats/readmissions (min) } \\
\hline Mean (SE) & $221.1(9.5)$ & $191.2(6.1)$ \\
\hline Median $(95 \% \mathrm{CI})$ & $196(189-210)$ & $178.5(171-188)$ \\
\hline \multicolumn{3}{|c|}{ Total CPB time, including repeats/readmissions (min) } \\
\hline Mean (SE) & $85.1(2.6)$ & $71.1(2.8)$ \\
\hline Median $(95 \% \mathrm{CI})$ & $82(77-87)$ & $66(59-74)$ \\
\hline \multicolumn{3}{|c|}{ Total cross-clamp time, including repeats/readmissions (min) } \\
\hline Mean (SE) & $66.1(1.6)$ & $53.5(2.0)$ \\
\hline Median $(95 \% \mathrm{CI})$ & $66(61-70)$ & $49(45-53)$ \\
\hline \multicolumn{3}{|c|}{ Volume of blood lost in the first 12 postoperative hours (mL) } \\
\hline Mean $(\mathrm{SD})$ & $310.4(342.5)$ & $323.2(267.8)$ \\
\hline Median (IQR) & $225(150-325)$ & $250(175-375)$ \\
\hline \multicolumn{3}{|c|}{ Transfusion of packed red cells in the first 48 postoperative hours (mL) } \\
\hline Number of transfused patients $(\%)$ & $50(42)$ & $51(49)$ \\
\hline Mean (SD) in transfused patients & $625.3(513.2)$ & $442.4(265.3)$ \\
\hline Median (IQR) in transfused patients & $500(300-644)$ & $303(284-569)$ \\
\hline \multicolumn{3}{|c|}{ Transfusion of clotting products in the first 48 postoperative hours $(\mathrm{mL})$} \\
\hline Number of transfused patients $(\%)$ & $11(9)$ & $4(4)$ \\
\hline Mean (SD) in transfused patients & $920.5(1438.4)$ & $753.0(672.5)$ \\
\hline Median (IQR) in transfused patients & $332(183-1050)$ & $625(209-1297)$ \\
\hline
\end{tabular}

All estimates for time-to-event endpoints are Kaplan-Meier estimates. Time data were complete, except for durations of 7 surgeries (3 min-sternotomy [MS], 4 full median sternotomy [FS]) that were not recorded and thus were censored at 1 minute. Blood data were missing for only 1 patient (FS group, withdrawn before surgery). Blood transfusion and clotting products data for 7 patients at the Freeman Hospital were recorded in units and converted to milliliters $(1$ unit of packed red cells $=300 \mathrm{~mL} ; 1$ unit of platelets $=245 \mathrm{~mL} ; 1$ unit of fresh-frozen plasma $=280 \mathrm{~mL}$ ). Transfusion data were explored using logistic regression models, including fixed effects for treatment, valve, and sex and a random surgeon effect. These analyses did not show a statistically significant difference between MS and FS patients in either need for blood transfusion (MS/FS odds ratio [OR], $0.797 ; 95 \% \mathrm{CI}, 0.453-1.402 ; P=.4310$ ) or the need for transfusion of clotting products (MS/FS OR, 2.616; $95 \% \mathrm{CI}, 0.801-8.541 ; P=.1112$ ). $S E$, Standard error; $C I$, confidence interval; $C P B$, cardiopulmonary bypass; $S D$, standard deviation; $I Q R$, interquartile range. 
TABLE E4. Results from cox models and log-rank tests for primary and secondary endpoints

\begin{tabular}{|c|c|c|c|c|}
\hline Endpoint & $\begin{array}{c}\text { MS/FS HR } \\
(95 \% \text { CI })\end{array}$ & $\begin{array}{c}P \text { value, } \\
\text { null hypothesis, } \\
\text { HR }=1\end{array}$ & $\begin{array}{c}\text { Log-rank } \\
\text { test statistic }\end{array}$ & $\begin{array}{c}P \text { value, } \\
\text { log-rank test }\end{array}$ \\
\hline \multicolumn{5}{|l|}{ Primary analyses } \\
\hline Time to discharge & $0.874(0.668-1.143)$ & .3246 & 0.157 & .6924 \\
\hline Time until fit & $0.907(0.688-1.197)$ & .4914 & 0.340 & .5597 \\
\hline \multicolumn{5}{|l|}{ Per-protocol analyses of primary endpoints } \\
\hline Time to discharge & $0.868(0.656-1.147)$ & .3194 & 0.200 & .6544 \\
\hline Time until fit & $0.915(0.688-1.218)$ & .5443 & 0.217 & .6415 \\
\hline \multicolumn{5}{|c|}{ Sensitivity analyses: age included as an effect in the Cox models } \\
\hline Time to discharge & $0.866(0.661-1.135)$ & .2985 & 0.157 & .6924 \\
\hline Time until fit & $0.902(0.683-1.192)$ & .4685 & 0.340 & .5597 \\
\hline \multicolumn{5}{|c|}{ Sensitivity analyses: EuroSCORE included as an effect in the Cox models } \\
\hline Time to discharge & $0.885(0.676-1.159)$ & .3753 & 0.157 & .6924 \\
\hline Time until fit & $0.936(0.709-1.236)$ & .6400 & 0.340 & .5597 \\
\hline \multicolumn{5}{|l|}{ Sensitivity analyses: censoring times taken as event times } \\
\hline Time to discharge & $0.884(0.677-1.153)$ & .3625 & 0.189 & .6639 \\
\hline Time until fit & $0.888(0.680-1.160)$ & .3844 & 0.765 & .3819 \\
\hline \multicolumn{5}{|l|}{ Sensitivity analysis: patients assumed to be fit at discharge } \\
\hline Time until fit & $0.879(0.671-1.151)$ & .3480 & 0.703 & .4018 \\
\hline \multicolumn{5}{|l|}{ Secondary endpoint analyses } \\
\hline Time until first mobilization & $0.899(0.680-1.187)$ & .4518 & 0.303 & .5819 \\
\hline Time until drain removal & $0.587(0.442-0.778)$ & .0002 & 5.838 & .0157 \\
\hline Time until first extubation & $0.856(0.655-1.120)$ & .2582 & 0.359 & .5488 \\
\hline \multicolumn{5}{|l|}{ Exploratory analyses } \\
\hline Surgery duration & $0.660(0.500-0.872)$ & .0035 & 17.892 & $<.0001$ \\
\hline $\mathrm{CPB}$ time & $0.592(0.448-0.782)$ & .0002 & 24.871 & $<.0001$ \\
\hline Cross-clamp time & $0.451(0.340-0.597)$ & $<.0001$ & 42.539 & $<.0001$ \\
\hline Theatre time & $0.665(0.503-0.879)$ & .0042 & 16.806 & $<.0001$ \\
\hline Total CPB time including repeats/readmissions & $0.547(0.414-0.723)$ & $<.0001$ & 20.176 & $<.0001$ \\
\hline Total cross-clamp time including repeats/readmissions & $0.458(0.346-0.608)$ & $<.0001$ & 34.352 & $<.0001$ \\
\hline Total theatre time including repeats/readmissions & $0.698(0.531-0.918)$ & .0102 & 5.657 & .0174 \\
\hline Time to death by any cause & $1.871(0.723-4.844)$ & .1966 & 0.7309 & .3926 \\
\hline
\end{tabular}

The table presents the results of all analyses performed for the primary and secondary time-to-event endpoints, including unplanned, exploratory analyses of secondary endpoints. All secondary endpoint analyses, sensitivity analyses, and exploratory analyses were performed using the intent-to-treat population. All log-rank tests were stratified by valve, sex, and surgeon. All Cox models included valve, sex, and treatment as fixed effects and surgeon as a random effect. Exploratory analysis of time to all-cause death included age as a fixed effect in the Cox model. Mean imputation was used for missing EuroSCORE data at baseline (1 MS). MS, Mini-sternotomy; $F S$, full median sternotomy; $H R$, hazard ratio; $C I$, confidence interval; $C P B$, cardiopulmonary bypass. 
TABLE E5. Pain at rest scores in the first 10 days following surgery

\begin{tabular}{|c|c|c|}
\hline Day & $\begin{array}{l}\text { Mini-sternotomy } \\
\quad(\mathbf{n}=118)\end{array}$ & $\begin{array}{l}\text { Full sternotomy } \\
\qquad(\mathbf{n}=104)\end{array}$ \\
\hline \multicolumn{3}{|l|}{ Day 1} \\
\hline Mean (SD) & $3.5(2.5)$ & $3.7(2.4)$ \\
\hline Number $(\%)$ & $100(85)$ & $82(80)$ \\
\hline \multicolumn{3}{|l|}{ Day 2} \\
\hline Mean (SD) & $3(2.3)$ & $3.1(2.5)$ \\
\hline Number (\%) & $89(75)$ & $81(79)$ \\
\hline \multicolumn{3}{|l|}{ Day 3} \\
\hline Mean (SD) & $2.7(2.3)$ & $2.4(2.3)$ \\
\hline Number $(\%)$ & $91(77)$ & $83(81)$ \\
\hline \multicolumn{3}{|l|}{ Day 4} \\
\hline Mean (SD) & $2.4(2.1)$ & $2.4(2.4)$ \\
\hline Number (\%) & $94(80)$ & $84(82)$ \\
\hline \multicolumn{3}{|l|}{ Day 5} \\
\hline Mean (SD) & $2(1.9)$ & $2.1(2)$ \\
\hline Number $(\%)$ & $90(79)$ & $80(79)$ \\
\hline \multicolumn{3}{|l|}{ Day 6} \\
\hline Mean (SD) & $1.8(1.7)$ & $2.1(2)$ \\
\hline Number $(\%)$ & $69(77)$ & $61(76)$ \\
\hline \multicolumn{3}{|l|}{ Day 7} \\
\hline Mean (SD) & $1.5(1.8)$ & $1.8(2)$ \\
\hline Number $(\%)$ & $46(69)$ & $42(78)$ \\
\hline \multicolumn{3}{|l|}{ Day 8} \\
\hline Mean (SD) & $1.2(1.4)$ & $1.7(1.6)$ \\
\hline Number $(\%)$ & $40(77)$ & $35(76)$ \\
\hline \multicolumn{3}{|l|}{ Day 9} \\
\hline Mean (SD) & $1(1.8)$ & $0.8(1.5)$ \\
\hline Number (\%) & $25(57)$ & $18(47)$ \\
\hline \multicolumn{3}{|l|}{ Day 10} \\
\hline Mean (SD) & $0.7(1)$ & $1.3(2)$ \\
\hline Number $(\%)$ & $18(47)$ & $12(43)$ \\
\hline
\end{tabular}

The denominator used for each percentage is the number of patients known to be alive and in the hospital on the given day. $S D$, Standard deviation.
TABLE E6. EQ-5D utility scores up to the 12-month follow-up

\begin{tabular}{|c|c|c|}
\hline Time & $\begin{array}{l}\text { Mini-sternotomy } \\
\quad(\mathbf{n}=118)\end{array}$ & $\begin{array}{l}\text { Full sternotomy } \\
\qquad(\mathrm{n}=\mathbf{1 0 4})\end{array}$ \\
\hline \multicolumn{3}{|l|}{ Baseline } \\
\hline Mean (SD) & $0.77(0.19)$ & $0.70(0.24)$ \\
\hline Number (\%) & $105(89)$ & $95(91)$ \\
\hline \multicolumn{3}{|l|}{ Day 4} \\
\hline Mean (SD) & $0.47(0.29)$ & $0.39(0.28)$ \\
\hline Number (\%) & $92(78)$ & $89(86)$ \\
\hline \multicolumn{3}{|l|}{ Discharge } \\
\hline Mean (SD) & $0.60(0.24)$ & $0.58(0.24)$ \\
\hline Number (\%) & $103(87)$ & $88(85)$ \\
\hline \multicolumn{3}{|l|}{$6 \mathrm{wk}$} \\
\hline Mean (SD) & $0.74(0.23)$ & $0.71(0.21)$ \\
\hline Number (\%) & $106(90)$ & $88(85)$ \\
\hline \multicolumn{3}{|l|}{$6 \mathrm{mo}$} \\
\hline Mean (SD) & $0.83(0.25)$ & $0.83(0.23)$ \\
\hline Number (\%) & $105(89)$ & $95(91)$ \\
\hline \multicolumn{3}{|l|}{$12 \mathrm{mo}$} \\
\hline Mean (SD) & $0.83(0.29)$ & $0.78(0.28)$ \\
\hline Number (\%) & $103(87)$ & $84(81)$ \\
\hline
\end{tabular}

For patients who died, EQ-5D scores were taken to be 0 following death. Percentages presented in the table were calculated as the number of scores recorded (including the 0 s) divided by the number of patients randomized to the group. The difference in mean baseline score was potentially due to the imbalance in sex; the full sternotomy group had a greater proportion of females, who reported lower quality of life on average. $S D$, Standard deviation. 
TABLE E7. SF-36 domain scores up to the 12-month follow-up

\begin{tabular}{|c|c|c|}
\hline Domain & $\begin{array}{l}\text { Mini-sternotomy } \\
\quad(\mathbf{n}=\mathbf{1 1 8})\end{array}$ & $\begin{array}{l}\text { Full sternotomy } \\
\quad(\mathbf{n}=\mathbf{1 0 4})\end{array}$ \\
\hline \multicolumn{3}{|l|}{ Bodily pain } \\
\hline \multicolumn{3}{|l|}{ Baseline } \\
\hline Mean (SD) & $70(25)$ & $64(28)$ \\
\hline Number (\%) & $104(88)$ & $96(92)$ \\
\hline \multicolumn{3}{|l|}{$6 \mathrm{wk}$} \\
\hline Mean (SD) & $61(24)$ & $60(23)$ \\
\hline Number $(\%)$ & $105(89)$ & $90(87)$ \\
\hline \multicolumn{3}{|l|}{$6 \mathrm{mo}$} \\
\hline Mean (SD) & 79 (27) & $74(28)$ \\
\hline Number (\%) & $104(88)$ & $94(90)$ \\
\hline \multicolumn{3}{|l|}{$12 \mathrm{mo}$} \\
\hline Mean (SD) & $76(31)$ & $72(32)$ \\
\hline Number $(\%)$ & $99(84)$ & $86(83)$ \\
\hline \multicolumn{3}{|l|}{ General health } \\
\hline \multicolumn{3}{|l|}{ Baseline } \\
\hline Mean (SD) & $62(20)$ & $58(22)$ \\
\hline Number $(\%)$ & $104(88)$ & $94(90)$ \\
\hline \multicolumn{3}{|l|}{$6 \mathrm{wk}$} \\
\hline Mean (SD) & $70(20)$ & $66(20)$ \\
\hline Number $(\%)$ & $104(88)$ & $91(88)$ \\
\hline \multicolumn{3}{|l|}{$6 \mathrm{mo}$} \\
\hline Mean (SD) & $71(24)$ & $66(24)$ \\
\hline Number $(\%)$ & $103(87)$ & $94(90)$ \\
\hline \multicolumn{3}{|l|}{$12 \mathrm{mo}$} \\
\hline Mean (SD) & $68(26)$ & $62(26)$ \\
\hline Number $(\%)$ & $100(85)$ & $86(83)$ \\
\hline \multicolumn{3}{|l|}{ Mental health } \\
\hline \multicolumn{3}{|l|}{ Baseline } \\
\hline Mean (SD) & 74 (18) & $67(21)$ \\
\hline Number $(\%)$ & $104(88)$ & $95(91)$ \\
\hline \multicolumn{3}{|l|}{$6 \mathrm{wk}$} \\
\hline Mean (SD) & $72(22)$ & $73(19)$ \\
\hline Number $(\%)$ & $104(88)$ & $91(88)$ \\
\hline \multicolumn{3}{|l|}{$6 \mathrm{mo}$} \\
\hline Mean (SD) & $80(21)$ & $74(22)$ \\
\hline Number $(\%)$ & $103(87)$ & $94(90)$ \\
\hline \multicolumn{3}{|l|}{$12 \mathrm{mo}$} \\
\hline Mean (SD) & $76(26)$ & $73(23)$ \\
\hline Number $(\%)$ & $100(85)$ & $86(83)$ \\
\hline \multicolumn{3}{|c|}{ Physical functioning } \\
\hline \multicolumn{3}{|c|}{ Baseline } \\
\hline Mean (SD) & $54(26)$ & $47(28)$ \\
\hline Number $(\%)$ & $105(89)$ & $96(92)$ \\
\hline \multicolumn{3}{|l|}{$6 \mathrm{wk}$} \\
\hline Mean (SD) & $63(22)$ & $56(23)$ \\
\hline Number $(\%)$ & 105 (89) & $91(88)$ \\
\hline \multicolumn{3}{|l|}{$6 \mathrm{mo}$} \\
\hline Mean (SD) & 78 (27) & $70(28)$ \\
\hline Number $(\%)$ & $104(88)$ & $94(90)$ \\
\hline \multicolumn{3}{|l|}{$12 \mathrm{mo}$} \\
\hline Mean (SD) & 74 (30) & $67(31)$ \\
\hline Number (\%) & $100(85)$ & $86(83)$ \\
\hline \multicolumn{3}{|l|}{ Role emotional } \\
\hline
\end{tabular}

(Continued)
TABLE E7. Continued

\begin{tabular}{|c|c|c|}
\hline Domain & $\begin{array}{l}\text { Mini-sternotomy } \\
\quad(\mathbf{n}=118)\end{array}$ & $\begin{array}{l}\text { Full sternotomy } \\
\quad(n=104)\end{array}$ \\
\hline Mean (SD) & $67(40)$ & $55(46)$ \\
\hline Number $(\%)$ & $104(88)$ & $94(90)$ \\
\hline \multicolumn{3}{|l|}{$6 \mathrm{wk}$} \\
\hline Mean (SD) & $60(44)$ & $63(43)$ \\
\hline Number $(\%)$ & $104(88)$ & $90(87)$ \\
\hline \multicolumn{3}{|l|}{$6 \mathrm{mo}$} \\
\hline Mean (SD) & $81(35)$ & $72(42)$ \\
\hline Number (\%) & $104(88)$ & $94(90)$ \\
\hline \multicolumn{3}{|l|}{$12 \mathrm{mo}$} \\
\hline Mean (SD) & $76(39)$ & $71(42)$ \\
\hline Number $(\%)$ & $98(83)$ & $85(82)$ \\
\hline \multicolumn{3}{|l|}{ Role physical } \\
\hline \multicolumn{3}{|l|}{ Baseline } \\
\hline Mean (SD) & $33(41)$ & $23(38)$ \\
\hline Number $(\%)$ & $103(87)$ & $96(92)$ \\
\hline \multicolumn{3}{|l|}{$6 \mathrm{wk}$} \\
\hline Mean (SD) & $19(32)$ & $20(33)$ \\
\hline Number $(\%)$ & $103(87)$ & $90(87)$ \\
\hline \multicolumn{3}{|l|}{$6 \mathrm{mo}$} \\
\hline Mean (SD) & $65(42)$ & $59(44)$ \\
\hline Number (\%) & $103(87)$ & $94(90)$ \\
\hline \multicolumn{3}{|l|}{$12 \mathrm{mo}$} \\
\hline Mean (SD) & $64(44)$ & $52(46)$ \\
\hline Number (\%) & $98(83)$ & $85(82)$ \\
\hline \multicolumn{3}{|l|}{ Social functioning } \\
\hline \multicolumn{3}{|l|}{ Baseline } \\
\hline Mean (SD) & $66(30)$ & $61(29)$ \\
\hline Number $(\%)$ & $104(88)$ & $94(90)$ \\
\hline \multicolumn{3}{|l|}{$6 \mathrm{wk}$} \\
\hline Mean (SD) & $66(29)$ & $68(27)$ \\
\hline Number $(\%)$ & $104(88)$ & $91(88)$ \\
\hline \multicolumn{3}{|l|}{$6 \mathrm{mo}$} \\
\hline Mean (SD) & 85 (26) & $78(28)$ \\
\hline Number (\%) & $102(86)$ & $93(89)$ \\
\hline \multicolumn{3}{|l|}{$12 \mathrm{mo}$} \\
\hline Mean (SD) & $81(30)$ & $78(30)$ \\
\hline Number (\%) & $98(83)$ & $85(82)$ \\
\hline \multicolumn{3}{|l|}{ Vitality } \\
\hline \multicolumn{3}{|l|}{ Baseline } \\
\hline Mean (SD) & $46(25)$ & $40(23)$ \\
\hline Number $(\%)$ & $104(88)$ & $95(91)$ \\
\hline \multicolumn{3}{|l|}{$6 \mathrm{wk}$} \\
\hline Mean (SD) & $50(22)$ & $48(22)$ \\
\hline Number $(\%)$ & $104(88)$ & $90(87)$ \\
\hline \multicolumn{3}{|l|}{$6 \mathrm{mo}$} \\
\hline Mean (SD) & $64(23)$ & $57(23)$ \\
\hline Number $(\%)$ & $103(87)$ & $94(90)$ \\
\hline \multicolumn{3}{|l|}{$12 \mathrm{mo}$} \\
\hline Mean (SD) & $60(26)$ & $54(26)$ \\
\hline Number $(\%)$ & $100(85)$ & $86(83)$ \\
\hline
\end{tabular}

An in-house implementation of the standard scoring algorithm for the developmental version of the SF-36 was used. For the patients who died, SF-36 scores were taken to be 0 following death. Percentages presented in the table were calculated as the number of scores recorded (including the $0 \mathrm{~s}$ ) divided by the number of patients randomized to the group. The differences in mean baseline scores were potentially due to the imbalance in sex; the full sternotomy group had a greater proportion of females, who reported lower quality of life on average. $S D$, Standard deviation. 
TABLE E8. Estimated treatment effects (MS-FS) and treatment-time interactions for SF-36 domain scores up to 12 months, EQ-5D utility scores up to 12 months, and pain scores up to discharge

\begin{tabular}{|c|c|c|c|}
\hline Parameter & Effect (MS - FS) & $95 \% \mathrm{CI}$ & $P$ value \\
\hline \multicolumn{4}{|l|}{ Pain at rest $(\mathrm{n}=219)$} \\
\hline Treatment effect & 0.0 & $(-0.7$ to 0.6$)$ & .9766 \\
\hline Treatment-time $(\mathrm{d})$ interaction & 0.0 & $(-0.1$ to 0.1$)$ & .8190 \\
\hline \multicolumn{4}{|l|}{ EQ-5D utility scores $(\mathrm{n}=197)$} \\
\hline Treatment effect & 0.02 & $(-0.03$ to 0.07$)$ & .5148 \\
\hline Treatment-time (mo) interaction & 0.00 & $(-0.01$ to 0.01$)$ & .9731 \\
\hline \multicolumn{4}{|l|}{ SF-36 physical functioning $(\mathrm{n}=192)$} \\
\hline Treatment effect & 1.2 & $(-6.2$ to 8.7$)$ & .7414 \\
\hline Treatment-time (mo) interaction & 0.3 & $(-0.2$ to 0.9$)$ & .2387 \\
\hline \multicolumn{4}{|l|}{ SF-36 role physical $(\mathrm{n}=190)$} \\
\hline Treatment effect & -8.3 & $(-21.1$ to 4.5$)$ & .2025 \\
\hline Treatment-time (mo) interaction & 1.7 & (0.3 to 3.1$)$ & .0169 \\
\hline \multicolumn{4}{|l|}{ SF-36 bodily pain $(\mathrm{n}=191)$} \\
\hline Treatment effect & -0.7 & $(-9.1$ to 7.8$)$ & .8792 \\
\hline Treatment-time $(\mathrm{mo})$ interaction & 0.3 & $(-0.5$ to 1.1$)$ & .4331 \\
\hline \multicolumn{4}{|l|}{ SF-36 general health $(n=189)$} \\
\hline Treatment effect & -1.0 & $(-7.5$ to 5.5$)$ & .7710 \\
\hline Treatment-time $(\mathrm{mo})$ interaction & 0.3 & $(-0.2$ to 0.8$)$ & .2224 \\
\hline \multicolumn{4}{|l|}{ SF-36 vitality $(\mathrm{n}=190)$} \\
\hline Treatment effect & -2.1 & $(-8.8$ to 4.5$)$ & .5273 \\
\hline Treatment-time $(\mathrm{mo})$ interaction & 0.6 & (0.1 to 1.2$)$ & .0293 \\
\hline \multicolumn{4}{|l|}{ SF-36 social functioning $(\mathrm{n}=189)$} \\
\hline Treatment effect & -5.5 & $(-14.1$ to 3.1$)$ & .2093 \\
\hline Treatment-time $(\mathrm{mo})$ interaction & 1.0 & (0.2 to 1.7$)$ & .0183 \\
\hline \multicolumn{4}{|l|}{ SF-36 role emotional $(\mathrm{n}=189)$} \\
\hline Treatment effect & -6.2 & $(-18.6$ to 6.2$)$ & .3255 \\
\hline Treatment-time (mo) interaction & 1.1 & $(-0.1$ to 2.3$)$ & .0699 \\
\hline \multicolumn{4}{|l|}{ SF-36 mental health $(n=190)$} \\
\hline Treatment effect & -3.2 & $(-9.7$ to 3.4$)$ & .3431 \\
\hline Treatment-time $(\mathrm{mo})$ interaction & 0.5 & $(-0.0$ to 1.0$)$ & .0702 \\
\hline
\end{tabular}


TABLE E9. Estimated treatment effects (MS-FS) and treatment-time interactions for SF-36 domain scores up to 12 months, EQ-5D utility scores up to 12 months, and pain scores up to discharge, after multiple imputation of missing scores

\begin{tabular}{|c|c|c|c|}
\hline Parameter & Effect (MS - FS) & $95 \%$ CI & $P$ value \\
\hline \multicolumn{4}{|l|}{ Pain at rest } \\
\hline Treatment effect & 0.0 & $(-0.7$ to 0.6$)$ & .9059 \\
\hline Treatment-time (d) interaction & 0.0 & $(-0.1$ to 0.1$)$ & .9685 \\
\hline \multicolumn{4}{|l|}{ EQ-5D utility scores } \\
\hline Treatment effect & 0.01 & $(-0.04$ to 0.06$)$ & .8203 \\
\hline Treatment-time (mo) interaction & 0.00 & $(-0.01$ to 0.01$)$ & .9094 \\
\hline \multicolumn{4}{|l|}{ SF-36 physical functioning } \\
\hline Treatment effect & 2.0 & $(-4.9$ to 8.9$)$ & .5744 \\
\hline Treatment-time $(\mathrm{mo})$ interaction & 0.2 & $(-0.3$ to 0.8$)$ & .3996 \\
\hline \multicolumn{4}{|l|}{ SF-36 role physical } \\
\hline Treatment effect & -6.6 & $(-18.7$ to 5.4$)$ & .2808 \\
\hline Treatment-time (mo) interaction & 1.5 & (0.1 to 2.8$)$ & .0310 \\
\hline \multicolumn{4}{|l|}{ SF-36 bodily pain } \\
\hline Treatment effect & -0.1 & $(-9.0$ to 7.7$)$ & .9748 \\
\hline Treatment-time $(\mathrm{mo})$ interaction & 0.3 & $(-0.4$ to 1.1$)$ & .4091 \\
\hline \multicolumn{4}{|l|}{ SF-36 general health } \\
\hline Treatment effect & 1.1 & $(-5.0$ to 7.3$)$ & .7175 \\
\hline Treatment-time $(\mathrm{mo})$ interaction & 0.2 & $(-0.3$ to 0.7$)$ & .3373 \\
\hline \multicolumn{4}{|l|}{ SF-36 vitality } \\
\hline Treatment effect & -0.5 & $(-6.9$ to 5.9$)$ & .8798 \\
\hline Treatment-time (mo)interaction & 0.4 & $(-0.2$ to 1.0$)$ & .1733 \\
\hline \multicolumn{4}{|l|}{ SF-36 social functioning } \\
\hline Treatment effect & -4.4 & $(-12.4$ to 3.5$)$ & .2756 \\
\hline Treatment-time (mo) interaction & 0.7 & (0.0 to 1.5$)$ & .0589 \\
\hline \multicolumn{4}{|l|}{ SF-36 role emotional } \\
\hline Treatment effect & -4.6 & $(-16.4$ to 7.2$)$ & .4415 \\
\hline Treatment-time $(\mathrm{mo})$ interaction & 0.8 & $(-0.4$ to 2.0$)$ & .1790 \\
\hline \multicolumn{4}{|l|}{ SF-36 mental health } \\
\hline Treatment effect & -2.5 & $(-8.6$ to 3.5$)$ & .4113 \\
\hline Treatment-time $(\mathrm{mo})$ interaction & 0.4 & $(-0.1$ to 0.9$)$ & .1195 \\
\hline
\end{tabular}

The table presents the results from analyzing the questionnaire data using multiple imputation to handle missing observations, under a missing at random assumption. For each analysis, missing data were imputed from models that included all other variables used in the analysis, along with Canadian Cardiovascular Society grade and New York Heart Association grade as auxiliary variables. The method used was multiple imputation by chained equations with predictive mean matching. Estimates from 100 imputed datasets were combined using Rubin rules. Pain was imputed only for patients known to be alive and hospitalized, not for patients who had died or had already been discharged. Evidence of a greater rate of improvement over time for MS patients (statistically significant, positive interaction term) was seen for only 1 SF-36 domain. MS, Mini-sternotomy; FS, full sternotomy; $S F-36$, Short Form Health Survey; $C I$, confidence interval. 
TABLE E10. Summary of heart function (LVEF) and respiratory function $\left(\mathrm{FEV}_{\mathbf{1}}\right)$

\begin{tabular}{|c|c|c|}
\hline Parameter & $\begin{array}{l}\text { Mini-sternotomy } \\
\quad(\mathbf{n}=118)\end{array}$ & $\begin{array}{l}\text { Full sternotomy } \\
\qquad(\mathrm{n}=104)\end{array}$ \\
\hline \multicolumn{3}{|l|}{$\mathrm{FEV}_{1}$ (Liters) } \\
\hline \multicolumn{3}{|l|}{ Baseline visit } \\
\hline Mean (SD) & $2.3(0.7)$ & $2.3(0.8)$ \\
\hline Median (IQR) & $2.2(1.8-2.7)$ & $2.2(1.7-2.6)$ \\
\hline Number & 115 & 101 \\
\hline \multicolumn{3}{|l|}{ Discharge } \\
\hline Mean (SD) & $1.6(0.6)$ & $1.6(0.6)$ \\
\hline Median (IQR) & $1.5(1.2-1.8)$ & $1.5(1.2-1.9)$ \\
\hline Number & 82 & 69 \\
\hline \multicolumn{3}{|l|}{ 6-wk visit } \\
\hline Mean (SD) & $2.1(0.8)$ & $2.1(0.7)$ \\
\hline Median (IQR) & $2(1.5-2.5)$ & $1.9(1.6-2.5)$ \\
\hline Number & 92 & 84 \\
\hline \multicolumn{3}{|l|}{ 6-mo visit } \\
\hline Mean (SD) & $2.2(0.7)$ & $2.1(0.7)$ \\
\hline Median (IQR) & $2.1(1.7-2.6)$ & $1.9(1.4-2.4)$ \\
\hline Number & 91 & 82 \\
\hline \multicolumn{3}{|l|}{ LVEF (\%) } \\
\hline \multicolumn{3}{|l|}{ Baseline visit } \\
\hline Mean (SD) & $61.9(9.1)$ & $62.4(8.6)$ \\
\hline Median (IQR) & $62.5(57.5-67.5)$ & $63(57.5-67.0)$ \\
\hline Number & 117 & 101 \\
\hline \multicolumn{3}{|l|}{ Discharge } \\
\hline Mean (SD) & $59.9(9.7)$ & $59(10.2)$ \\
\hline Median (IQR) & $62(55.0-65.0)$ & $58(55.0-64.5)$ \\
\hline Number & 106 & 96 \\
\hline \multicolumn{3}{|l|}{ 6-mo visit } \\
\hline Mean (SD) & $61.2(8.1)$ & $61.8(9.7)$ \\
\hline Median (IQR) & $61(56.0-67.5)$ & $62.5(56.3-68.0)$ \\
\hline Number & 97 & 88 \\
\hline
\end{tabular}

No analyses were planned for these endpoints. $F E V_{l}$, Forced expiratory volume in 1 second (measured by hand-held spirometry); $S D$, standard deviation; $I Q R$, interquartile range; $L V E F$, left ventricular ejection fraction (measured by echocardiography).
TABLE E11. Frequency of nonfatal SAEs within 1 year of surgery, by treatment received

\begin{tabular}{|c|c|c|c|}
\hline Nonfatal SAE & $\begin{array}{c}\text { Mini- } \\
\text { sternotomy } \\
(\mathbf{n}=\mathbf{1 1 0}), \\
\% \text { (number) }\end{array}$ & $\begin{array}{c}\text { Full } \\
\text { sternotomy } \\
(\mathbf{n}=\mathbf{1 1 1}), \\
\% \text { (number) }\end{array}$ & $\begin{array}{c}\text { Total } \\
(\mathbf{n}=\mathbf{2 2 1}), \\
\% \text { (number) }\end{array}$ \\
\hline $\begin{array}{l}\text { Cardiac (including atrial } \\
\text { fibrillation, conduction } \\
\text { problems, need for } \\
\text { permanent pacemaker) }\end{array}$ & $43(29)$ & $27(21)$ & $70(50)$ \\
\hline Respiratory & $20(14)$ & $9(8)$ & $29(22)$ \\
\hline Injury/procedural & $19(11)$ & 7 (6) & $26(17)$ \\
\hline $\begin{array}{l}\text { Noncardiorespiratory } \\
\text { infection (including } \\
\text { wound) }\end{array}$ & $7(7)$ & $12(9)$ & $19(16)$ \\
\hline Urinary & $11(10)$ & $8(6)$ & $19(16)$ \\
\hline $\begin{array}{l}\text { Surgical and medical } \\
\text { procedures }\end{array}$ & $9(6)$ & $7(7)$ & $16(13)$ \\
\hline Nervous system & $8(8)$ & 7 (7) & $15(15)$ \\
\hline $\begin{array}{l}\text { Cardiorespiratory infection } \\
\text { (including endocarditis, } \\
\text { device-related infections, } \\
\text { chest infection) }\end{array}$ & $9(9)$ & $6(5)$ & $15(14)$ \\
\hline Vascular & $9(9)$ & $1(1)$ & $10(10)$ \\
\hline Psychiatric & $5(5)$ & $5(5)$ & $10(10)$ \\
\hline Gastrointestinal, diarrhea & $7(6)$ & $3(3)$ & $10(9)$ \\
\hline Gastrointestinal, other & $7(7)$ & $1(1)$ & $8(8)$ \\
\hline General disorders & $4(4)$ & $3(2)$ & $7(6)$ \\
\hline Metabolic & $2(2)$ & $3(2)$ & $5(4)$ \\
\hline Blood/lymph & $4(3)$ & $1(1)$ & $5(4)$ \\
\hline Neoplasms & $1(1)$ & $1(1)$ & $2(2)$ \\
\hline Hepatitis/cholecystitis & $1(1)$ & $1(1)$ & $2(2)$ \\
\hline Musculoskeletal & $2(2)$ & $0(0)$ & $2(2)$ \\
\hline Skin/tissue & $0(0)$ & $1(1)$ & $1(1)$ \\
\hline Eye & $0(0)$ & $1(1)$ & $1(1)$ \\
\hline Immune & $0(0)$ & $1(1)$ & $1(1)$ \\
\hline Total & $168(56)$ & $105(46)$ & $273(102)$ \\
\hline
\end{tabular}


TABLE E12. Frequency of nonfatal SAEs within 1 year of surgery at each level of severity, expectedness, and relatedness, by treatment received

\begin{tabular}{|c|c|c|c|}
\hline Nonfatal SAE & Mini-sternotomy $(\mathbf{n}=110), \%$ (number $)$ & Full sternotomy $(n=111), \%($ number $)$ & Total $(\mathbf{n}=221), \%($ number $)$ \\
\hline \multicolumn{4}{|l|}{ Cardiorespiratory } \\
\hline \multicolumn{4}{|l|}{ Severity } \\
\hline Severe & $26(14)$ & $14(11)$ & $40(25)$ \\
\hline Moderate & $34(24)$ & $24(18)$ & $58(42)$ \\
\hline Mild & $12(11)$ & $4(4)$ & $16(15)$ \\
\hline \multicolumn{4}{|l|}{ Expectedness } \\
\hline Expected & $69(38)$ & $42(30)$ & $111(68)$ \\
\hline Unexpected & $3(2)$ & $0(0)$ & $3(2)$ \\
\hline \multicolumn{4}{|l|}{ Relatedness } \\
\hline Probably related & $4(4)$ & $2(2)$ & $6(6)$ \\
\hline Possibly related & $50(30)$ & $32(25)$ & $82(55)$ \\
\hline Unrelated & $18(13)$ & $8(6)$ & $26(19)$ \\
\hline Total & $72(38)$ & $42(30)$ & $114(68)$ \\
\hline \multicolumn{4}{|l|}{ Noncardiorespiratory } \\
\hline \multicolumn{4}{|l|}{ Severity } \\
\hline Severe & $40(21)$ & $24(15)$ & $64(36)$ \\
\hline Moderate & $43(29)$ & $31(21)$ & $74(50)$ \\
\hline Mild & $13(11)$ & $8(5)$ & $21(16)$ \\
\hline \multicolumn{4}{|l|}{ Expectedness } \\
\hline Expected & $68(34)$ & $45(27)$ & $113(61)$ \\
\hline Unexpected & $28(15)$ & $18(15)$ & $46(30)$ \\
\hline \multicolumn{4}{|l|}{ Relatedness } \\
\hline Probably related & $9(5)$ & $5(5)$ & $14(10)$ \\
\hline Possibly related & $37(22)$ & $30(20)$ & $67(42)$ \\
\hline Unrelated & $50(27)$ & $28(20)$ & 78 (47) \\
\hline Total & $96(41)$ & $63(34)$ & $159(75)$ \\
\hline
\end{tabular}

The only unexpected events in the mini-sternotomy (MS) group were a bilateral pleural effusion in 1 patient, and bronchial aspiration and periarrest event in 1 patient. Both patients recovered completely. Exploratory analysis in the safety population, using logistic regression (with fixed treatment, valve, and sex effects and a random surgeon effect), did not show a statistically significant difference between MS and full sternotomy (FS) recipients in the odds of sustaining a nonfatal SAE within the first year (MS/FS odds ratio [OR], 1.559, 95\% confidence interval [CI], 0.895-2.715; $P=.1161$ ). An exploratory Poisson regression (with a fixed effect for treatment and a random patient effect) did show a greater rate of such SAEs for MS recipients (MS/FS rate ratio, $1.615 ; 95 \% \mathrm{CI}, 1.070-2.437 ; P=.0225$ ). There were 7 cases of pericardial tamponade (4 in FS recipients and 3 in MS recipients; only 1 per patient), but logistic regression (without the random surgeon effect) did not produce a statistically significant result (MS/FS OR, $0.680 ; 95 \%$ CI, $0.146-3.178 ; P=.6229)$. SAE, Significant adverse effect.

TABLE E13. Frequency of paraprosthetic regurgitation, by treatment received

\begin{tabular}{|c|c|c|c|}
\hline Parameter & Mini-sternotomy $(\mathrm{n}=110)$ & Full sternotomy $(n=111)$ & Total $(n=221)$ \\
\hline \multicolumn{4}{|l|}{ Discharge } \\
\hline No regurgitation & 84 & 85 & 169 \\
\hline Mild regurgitation & 19 & 16 & 35 \\
\hline Moderate regurgitation & 0 & 0 & 0 \\
\hline Severe regurgitation & 0 & 0 & 0 \\
\hline Total & 101 & 103 & 204 \\
\hline \multicolumn{4}{|l|}{ 6-mo visit } \\
\hline No regurgitation & 77 & 82 & 159 \\
\hline Mild regurgitation & 18 & 10 & 28 \\
\hline Moderate regurgitation & 0 & 0 & 0 \\
\hline Severe regurgitation & 0 & 0 & 0 \\
\hline Total & 95 & 92 & 187 \\
\hline
\end{tabular}

Paraposthetic regurgitation was explored using logistic regressions at each time point. These were performed as complete-case analyses in the safety population. Logistic regression models included fixed treatment, valve and sex effects, and a random surgeon effect. They did not show a statistically significant difference between mini-sternotomy (MS) recipients and full sternotomy (FS) recipients in the odds of regurgitation, either at discharge (MS/FS odds ratio [OR], 1.163, confidence interval [CI], $0.553-2.445 ; P=.6883)$ or at $6 \mathrm{mo}(\mathrm{MS} / \mathrm{FS}$ OR, $1.880 ; 95 \% \mathrm{CI}, 0.798-4.430 ; P=.1480)$. 
TABLE E14. All wound infections within the first year after surgery, by treatment received

\begin{tabular}{|c|c|c|}
\hline Treatment & Relationship & Description \\
\hline FS & Possibly related & Superficial sternal wound infection \\
\hline FS & Possibly related & Sternal wound infection; returned to theatre for debridement and wires removed \\
\hline FS & Possibly related & Sternal wound infection \\
\hline FS & Possibly related & $\begin{array}{l}\text { Sternal wound breakdown; debridement and excision of sinuses; peripherally inserted central catheter for } 6 \mathrm{wk} \text {; } \\
\text { intravenous antibiotics }\end{array}$ \\
\hline FS & Possibly related & Drain site wound infection \\
\hline FS & Possibly related & Wound infection, small area at lower end of sternum \\
\hline FS & Possibly related & Small sternal wound infection \\
\hline FS & Probably related & Sternal wound infection \\
\hline FS & Probably related & Sternal wound infection \\
\hline FS & Possibly related & Sternal wound infection \\
\hline FS & Probably related & Sternal wound infection \\
\hline FS & Possibly related & Sternal wound infection; antibiotic therapy initiated \\
\hline FS & Possibly related & Sternal wound infection requiring hospital admission; treated with antibiotics \\
\hline FS & Possibly related & Wound infection treated with antibiotics and daily dressing changes \\
\hline MS & Possibly related & Readmission, wound infection, intravenous/oral flucloxacillin \\
\hline MS & Possibly related & Methicillin-resistant Staphylococcus aureus sternal wound infection \\
\hline MS & Probably related & $\begin{array}{l}\text { Sternal wound infection; admitted with fever, chest pain, shortness of breath, and discharging sternal } \\
\text { wound; intravenous flucloxacillin initiated; swab taken; VAC dressing applied }\end{array}$ \\
\hline MS & Possibly related & Wound infection at base of sternotomy; wound swab taken, Klebsiella pneumoniae grown; amoxycillin initiated \\
\hline
\end{tabular}


TABLE E15. All deaths

\begin{tabular}{|c|c|c|c|c|c|}
\hline & $\begin{array}{c}\text { Treatment } \\
\text { received }\end{array}$ & $\begin{array}{l}\text { Treatment } \\
\text { allocated }\end{array}$ & Cause & $\begin{array}{l}\text { Relationship } \\
\text { to treatment }\end{array}$ & $\begin{array}{l}\text { Days from } \\
\text { surgery } \\
\text { to death }\end{array}$ \\
\hline \multirow[t]{11}{*}{ Cardiorespiratory } & FS & FS & Endocarditis and sepsis & Possibly related & 124 \\
\hline & FS & FS & Lung infection & Unrelated & 1050 \\
\hline & FS & FS & Respiratory failure, pneumonia, chronic lymphocytic leukemia & Unrelated & 1057 \\
\hline & MS & MS & $\begin{array}{l}\text { Cardiac arrest and pericardial tamponade } 2 \text { days after surgery; } \\
\text { heart failure and left anterior pneumothorax } 3 \text { days after surgery }\end{array}$ & Possibly related & 3 \\
\hline & MS & MS & Type 2 respiratory failure and shock, multiorgan failure & Possibly related & 24 \\
\hline & MS & MS & $\begin{array}{l}\text { Postoperative arrest in high-dependency unit on day of surgery; } \\
\text { heart failure } 26 \text { days after surgery }\end{array}$ & Possibly related & 26 \\
\hline & MS & MS & $\begin{array}{l}\text { Lower respiratory tract infection; type } 2 \text { respiratory failure; } \\
\text { non-ST-elevation myocardial infarction during hospital } \\
\text { admission }\end{array}$ & Unrelated & 75 \\
\hline & MS & MS & $\begin{array}{l}\text { Endocarditis, infected valve; refused all treatment, } \\
\text { including antibiotics; palliation only }\end{array}$ & Possibly related & 241 \\
\hline & MS & MS & Exacerbation of chronic obstructive pulmonary disease & Unrelated & 307 \\
\hline & MS & MS & Ischaemic heart disease & Unrelated & 502 \\
\hline & MS & MS & Myocardial infarction & Unrelated & 933 \\
\hline \multirow[t]{8}{*}{ Noncardiorespiratory } & FS & FS & Sepsis & Unrelated & 66 \\
\hline & FS & FS & Metastatic prostate cancer & Unrelated & 256 \\
\hline & FS & FS & B cell lymphoma & Unrelated & 308 \\
\hline & FS & FS & $\begin{array}{l}\text { Embolus of left common femoral artery, advanced } \\
\text { colorectal cancer, AS, congestive heart failure }\end{array}$ & Unrelated & 958 \\
\hline & MS & MS & Metastatic bladder cancer & Unrelated & 257 \\
\hline & MS & MS & Death due to malignant tumor of esophagus & Unrelated & 445 \\
\hline & MS & MS & Diffuse large B cell lymphoma & Unrelated & 527 \\
\hline & MS & MS & Spontaneous subdural hemorrhage & Unrelated & 873 \\
\hline
\end{tabular}

The table shows that none of the patients who died were considered crossovers from MS to FS; however, there were 3 deaths among patients who were allocated to and received MS but who were returned to the theatre for redo FS. These were the deaths, all categorized as cardiorespiratory, occurring at 3, 26, and 933 days after surgery. FS, Full sternotomy; $M S$, mini-sternotomy; $A S$, ankylosing spondylitis. 
TABLE E16. Unit costs

\begin{tabular}{|c|c|c|c|}
\hline Item & Source & Consultation time/code & $\begin{array}{c}\text { Mean (SD), } £ \text {, } \\
2014 / 15\end{array}$ \\
\hline General practitioner visits & PSSRU 2015. 10.8b & Per patient contact lasting $17.2 \mathrm{~min}$ & $65.00(13.00)$ \\
\hline General practitioner home visits & PSSRU 2015. 10.8b & Per patient contact lasting $11.7 \mathrm{~min}$ & $45.00(9.00)$ \\
\hline Nurse (general practitioner practice) visits & PSSRU 2015. 10.6 & Per patient contact $15.5 \mathrm{~min}$ & $14.47(2.89)$ \\
\hline Nurse (specialist community) home visits & PSSRU 2015. 10.4 & Per patient contact $15.5 \mathrm{~min}$ & $19.38(3.88)$ \\
\hline Physiotherapy (outpatient) & NHS Ref 2014-15 & Code: WF01A & $16.13(3.23)$ \\
\hline Occupational therapy (outpatient) & NHS Ref 2014-15 & Code: WF01A & $16.67(3.33)$ \\
\hline Physiotherapy (inpatient) & PSSRU 2015. 13.1 & Per patient contact lasting $20 \mathrm{~min}$ & $12.67(2.53)$ \\
\hline Occupational therapy (inpatient) & PSSRU 2015. 13.2 & Per patient contact lasting $20 \mathrm{~min}$ & $12.67(2.53)$ \\
\hline Physiotherapy (home) & PSSRU 2015. 8.4.1 & Per patient contact lasting $20 \mathrm{~min}$ & $27.00(5.40)$ \\
\hline Theatre use & Papworth estimate & & $20.00(4.00)$ \\
\hline Horizontal surgical saw & Papworth estimate & 20-year life span and are used in & $3138.22(3.1)$ \\
\hline Pediatric internal cardioversion paddles & & 255 surgeries in every $5 \mathrm{y}$ & $161.71(0.2)$ \\
\hline Internal paddle handle & & & $670.00(0.7)$ \\
\hline $\begin{array}{l}\text { Reprocessing cost of defibrillator paddles } \\
\text { for each surgery* }\end{array}$ & & Per patient & $2.40(2.40)$ \\
\hline Single-use saw blade for mini-sternotomy & & Per patient & $15.80(15.80)$ \\
\hline Single-use saw blade for full sternotomy & & Per patient & $48.00(48.00)$ \\
\hline Adult critical care & NHS Ref 2014-15 & Total/weighted average & $1274.92(583.33)$ \\
\hline Specialized ward & NHS Ref 2014-15 & Code: SD01A & $387.96(77.59)$ \\
\hline General ward & NHS Ref 2014-15 & Code: SD03A & $103.01(20.60)$ \\
\hline Rehabilitation & PSSRU (1.3) 2015 & & $158.57(31.71)$ \\
\hline 24-h blood pressure monitoring & Lovibond et al, 2011 ${ }^{\mathrm{E} 3}$ & & $61.47(12.29)$ \\
\hline Radiography (chest) & Auguste et al, 2011 ${ }^{\mathrm{E} 4}$ & & $3.46(0.69)$ \\
\hline Transthoracic echocardiography & NHS Ref 2014-15 & Simple echocardiography & $83.94(16.79)$ \\
\hline Transesophageal echocardiography & NHS Ref 2014-15 & Complex echocardiography & $128.49(25.70)$ \\
\hline Stress echocardiography & NHS Ref 2014-15 & Complex echocardiography & $128.49(25.70)$ \\
\hline 24-h electrocardiography & NHS Ref 2014-15 & Electrocardiography monitoring & $140.69(28.14)$ \\
\hline 12-h electrocardiography & NHS Ref 2014-15 & Electrocardiography monitoring & $140.69(28.14)$ \\
\hline Exercise tolerance test & NHS Ref 2014-15 & Electrocardiography monitoring & $140.69(28.14)$ \\
\hline Magnetic resonance imaging & NHS Ref 2014-15 & Total/weighted average & $146.15(56.64)$ \\
\hline Full pulmonary function testing & NHS Ref 2014-15 & Code: DZ52Z & $55.32(11.06)$ \\
\hline Cardiac rehabilitation & NHS Ref 2014-15 & Code: VC38Z & $97.84(19.57)$ \\
\hline Cardiology clinic & NHS Ref 2014-15 & Code: WF01A & $123.02(24.60)$ \\
\hline Pacemaker & NHS Ref 2014-15 & Code: EY08E & $76.32(15.26)$ \\
\hline Blood tests & NHS Ref 2014-15 & Code: DAPS08 & $3.46(0.69)$ \\
\hline Arrhythmia clinic & NHS Ref 2014-15 & Total/weighted average & $131.14(26.23)$ \\
\hline Wound clinic & NHS Ref 2014-15 & Code: N25AF/AN & $54.93(10.99)$ \\
\hline Accident and emergency visit & NHS Ref 2014-15 & Total/weighted average & $140.59(141.05)$ \\
\hline Computed tomography scan & NHS Ref 2014-15 & Total/weighted average & $122.31(48.86)$ \\
\hline
\end{tabular}

SD, Standard deviation; $P S S R U$, Personal Social Services Research Unit; NHS, National Health Service. *The lead clinician confirmed that the defibrillator is not routinely used, that the cost of paddles should apply to $30 \%$ of patients, and that the cost of external defibrillator plates should be excluded for mini-sternotomy, because the plate is used only when it is not possible to insert the paddles. 
TABLE E17. Summary of resource use (without imputation)

\begin{tabular}{|c|c|c|c|c|c|}
\hline \multirow[b]{2}{*}{ Primary admission costs } & \multirow[b]{2}{*}{$\begin{array}{c}\text { Unit of } \\
\text { measurement }\end{array}$} & \multicolumn{2}{|c|}{ Full sternotomy } & \multicolumn{2}{|c|}{ Mini-sternotomy } \\
\hline & & Observations & $\begin{array}{c}\text { Mean (SD) } \\
\text { resource use/ } \\
\text { patient }\end{array}$ & Observations & $\begin{array}{c}\text { Mean (SD) } \\
\text { resource use/ } \\
\text { patient }\end{array}$ \\
\hline Theatre & Minutes & 104 & $191.19(62.15)$ & 118 & $221.11(102.65)$ \\
\hline Critical care (intensive therapy unit) & Hours & 103 & $34.67(57.17)$ & 118 & $55.24(94.69)$ \\
\hline Cardiac ward & Days & 103 & $7.09(4.31)$ & 118 & $6.90(3.87)$ \\
\hline Rehabilitation* & Days & 103 & $2.45(11.90)$ & 117 & $1.68(10.27)$ \\
\hline Acute hospital* & Days & 103 & $0.90(4.97)$ & 117 & $0.74(5.09)$ \\
\hline Physiotherapy (inpatient) & Days & 103 & $5.90(4.21)$ & 117 & $5.90(5.16)$ \\
\hline Occupational therapy (inpatient) & Days & 103 & $0.17(0.58)$ & 118 & $0.24(0.69)$ \\
\hline \multicolumn{6}{|l|}{ Follow-up (postdischarge) } \\
\hline Intensive therapy unit & Days & 81 & $0.00(0.00)$ & 94 & $0.03(0.31)$ \\
\hline General ward & Days & 92 & $2.87(14.37)$ & 101 & $0.86(3.43)$ \\
\hline Cardiac ward & Days & 92 & $0.40(1.49)$ & 100 & $1.15(4.32)$ \\
\hline 24-h blood pressure monitoring & Number of tests & 80 & $0.16(0.56)$ & 94 & $0.19(1.26)$ \\
\hline Radiography (chest) & Number of tests & 80 & $0.49(0.89)$ & 94 & $0.64(0.90)$ \\
\hline Computed tomography scan & Number of tests & 80 & $0.14(0.52)$ & 94 & $0.15(0.51)$ \\
\hline Transthoracic echocardiography & Number of tests & 80 & $0.41(0.69)$ & 94 & $0.55(0.84)$ \\
\hline Transesophageal echocardiography & Number of tests & 80 & $0.03(0.22)$ & 92 & $0.03(0.18)$ \\
\hline Stress echocardiography & Number of tests & 80 & $0.01(0.11)$ & 93 & $0.01(0.10)$ \\
\hline 24-h electrocardiography & Number of tests & 80 & $0.11(0.39)$ & 94 & $0.15(0.46)$ \\
\hline 12-h electrocardiography & Number of tests & 80 & $0.69(0.91)$ & 94 & $0.90(1.18)$ \\
\hline Exercise tolerance test & Number of tests & 80 & $0.08(0.27)$ & 93 & $0.06(0.25)$ \\
\hline Magnetic resonance imaging & Number of tests & 79 & $0.03(0.16)$ & 94 & $0.05(0.23)$ \\
\hline Full pulmonary function testing & Number of tests & 80 & $0.05(0.22)$ & 94 & $0.03(0.18)$ \\
\hline Blood test & Number of tests & 81 & $0.05(0.22)$ & 94 & $0.06(0.35)$ \\
\hline Accident and emergency visit & Number of visits & 80 & $0.09(0.28)$ & 94 & $0.22(0.51)$ \\
\hline Arrhythmia clinic & Number of visits & 80 & $0.03(0.16)$ & 94 & $0.00(0.00)$ \\
\hline Cardiac rehabilitation & Number of visits & 79 & $0.84(2.76)$ & 93 & $0.32(1.43)$ \\
\hline Cardiology clinic & Number of visits & 79 & $0.48(0.68)$ & 94 & $0.49(0.73)$ \\
\hline General practitioner home visits & Number of visits & 79 & $0.23(0.64)$ & 94 & $0.30(0.75)$ \\
\hline General practitioner visits & Number of visits & 80 & $2.00(2.34)$ & 94 & $2.20(2.31)$ \\
\hline Nurse (specialist community) home visits & Number of visits & 80 & $0.31(1.12)$ & 94 & $0.39(1.18)$ \\
\hline Nurse (general practice) visits & Number of visits & 80 & $2.10(10.02)$ & 92 & $0.75(1.46)$ \\
\hline Occupational therapy (outpatient) & Number of visits & 80 & $0.11(0.71)$ & 94 & $0.06(0.62)$ \\
\hline Pacemaker & Number of visits & 79 & $0.08(0.68)$ & 93 & $0.06(0.38)$ \\
\hline Physiotherapy (home) & Number of visits & 80 & $0.05(0.35)$ & 94 & $0.00(0.00)$ \\
\hline Physiotherapy (outpatient) & Number of visits & 80 & $0.04(0.19)$ & 94 & $0.01(0.10)$ \\
\hline Wound clinic & Number of visits & 80 & $0.06(0.29)$ & 94 & $0.02(0.15)$ \\
\hline
\end{tabular}

$S D$, Standard deviation. *Discharged to convalescence/long term care/acute hospital instead of to home. 
TABLE E18. Missing follow-up resource use

\begin{tabular}{|c|c|c|c|}
\hline Follow-up resource use & Full sternotomy, number & Mini-sternotomy, number & Total, number \\
\hline \multicolumn{4}{|l|}{$6 \mathrm{wk}$} \\
\hline Missing & 3 & 4 & 7 \\
\hline Lost to follow-up & 4 & 6 & 10 \\
\hline Dead & 1 & 4 & 5 \\
\hline Observations & 96 & 104 & 200 \\
\hline \multicolumn{4}{|l|}{$6 \mathrm{mo}$} \\
\hline Missing & 2 & 5 & 7 \\
\hline Lost to follow-up & 8 & 9 & 17 \\
\hline Dead & 2 & 6 & 8 \\
\hline Observations & 92 & 98 & 190 \\
\hline \multicolumn{4}{|l|}{$12 \mathrm{mo}$} \\
\hline Missing & 9 & 4 & 13 \\
\hline Lost to follow-up & 11 & 13 & 24 \\
\hline Dead & 4 & 7 & 11 \\
\hline Observations & 80 & 94 & 174 \\
\hline Total & 104 & 118 & 222 \\
\hline
\end{tabular}




\begin{tabular}{|c|c|c|c|c|c|c|c|c|}
\hline \multirow[b]{2}{*}{ Resource use } & \multicolumn{4}{|c|}{ Full sternotomy } & \multicolumn{4}{|c|}{ Mini-sternotomy } \\
\hline & Complete & Incomplete & Imputed & Total & Complete & Incomplete & Imputed & Total \\
\hline \multicolumn{9}{|l|}{ Primary admission } \\
\hline Theatre time (min) & 104 & 0 & 0 & 104 & 118 & 0 & 0 & 118 \\
\hline Critical care stay (h) & 103 & 1 & 1 & 104 & 118 & 0 & 0 & 118 \\
\hline Cardiac ward stay (d) & 103 & 1 & 1 & 104 & 118 & 0 & 0 & 118 \\
\hline Rehabilitation days* & 103 & 1 & 1 & 104 & 117 & 1 & 1 & 118 \\
\hline Acute hospital days* & 103 & 1 & 1 & 104 & 117 & 1 & 1 & 118 \\
\hline Physiotherapy visits & 103 & 1 & 1 & 104 & 117 & 1 & 1 & 118 \\
\hline Occupational therapy visits & 103 & 1 & 1 & 104 & 118 & 0 & 0 & 118 \\
\hline \multicolumn{9}{|l|}{ Follow-up (postdischarge) } \\
\hline Postdischarge intensive therapy unit days & 81 & 23 & 23 & 104 & 94 & 24 & 24 & 118 \\
\hline Postdischarge general ward stay & 92 & 12 & 12 & 104 & 101 & 17 & 17 & 118 \\
\hline Postdischarge cardiac ward stay & 92 & 12 & 12 & 104 & 100 & 18 & 18 & 118 \\
\hline $24 \mathrm{~h}$ blood pressure monitoring & 80 & 24 & 24 & 104 & 94 & 24 & 24 & 118 \\
\hline Radiography (chest) & 80 & 24 & 24 & 104 & 94 & 24 & 24 & 118 \\
\hline Computed tomography scan & 80 & 24 & 24 & 104 & 94 & 24 & 24 & 118 \\
\hline Transthoracic echocardiography & 80 & 24 & 24 & 104 & 94 & 24 & 24 & 118 \\
\hline Transesophageal echocardiography & 80 & 24 & 24 & 104 & 92 & 26 & 26 & 118 \\
\hline Stress echocardiography & 80 & 24 & 24 & 104 & 93 & 25 & 25 & 118 \\
\hline 24-h electrocardiography & 80 & 24 & 24 & 104 & 94 & 24 & 24 & 118 \\
\hline 12-h electrocardiography & 80 & 24 & 24 & 104 & 94 & 24 & 24 & 118 \\
\hline Exercise tolerance test & 80 & 24 & 24 & 104 & 93 & 25 & 25 & 118 \\
\hline Magnetic resonance imaging & 79 & 25 & 25 & 104 & 94 & 24 & 24 & 118 \\
\hline Pulmonary function testing & 80 & 24 & 24 & 104 & 94 & 24 & 24 & 118 \\
\hline Blood tests & 81 & 23 & 23 & 104 & 94 & 24 & 24 & 118 \\
\hline Accident and emergency visit & 80 & 24 & 24 & 104 & 94 & 24 & 24 & 118 \\
\hline Arrhythmia clinic & 80 & 24 & 24 & 104 & 94 & 24 & 24 & 118 \\
\hline Cardiac rehabilitation & 79 & 25 & 25 & 104 & 93 & 25 & 25 & 118 \\
\hline Cardiology clinic & 79 & 25 & 25 & 104 & 94 & 24 & 24 & 118 \\
\hline General practitioner home visits & 79 & 25 & 25 & 104 & 94 & 24 & 24 & 118 \\
\hline General practitioner visits & 80 & 24 & 24 & 104 & 94 & 24 & 24 & 118 \\
\hline Nurse (specialist community) home visits & 80 & 24 & 24 & 104 & 94 & 24 & 24 & 118 \\
\hline Nurse (general practice) visits & 80 & 24 & 24 & 104 & 92 & 26 & 26 & 118 \\
\hline Occupational therapy & 80 & 24 & 24 & 104 & 94 & 24 & 24 & 118 \\
\hline Pacemaker & 79 & 25 & 25 & 104 & 93 & 25 & 25 & 118 \\
\hline Physiotherapy (home) & 80 & 24 & 24 & 104 & 94 & 24 & 24 & 118 \\
\hline Physiotherapy & 80 & 24 & 24 & 104 & 94 & 24 & 24 & 118 \\
\hline Wound clinic & 80 & 24 & 24 & 104 & 94 & 24 & 24 & 118 \\
\hline \multicolumn{9}{|l|}{ EQ-5D score } \\
\hline Baseline & 95 & 9 & 9 & 104 & 105 & 13 & 13 & 118 \\
\hline $4 \mathrm{~d}$ postoperation & 89 & 15 & 15 & 104 & 92 & 26 & 26 & 118 \\
\hline Discharge & 88 & 16 & 16 & 104 & 103 & 15 & 15 & 118 \\
\hline 6-wk follow-up & 88 & 16 & 16 & 104 & 106 & 12 & 12 & 118 \\
\hline 6-mo follow-up & 95 & 9 & 9 & 104 & 105 & 13 & 13 & 118 \\
\hline 12-mo follow-up & 84 & 20 & 20 & 104 & 103 & 15 & 15 & 118 \\
\hline \multicolumn{9}{|l|}{ SF-6D score } \\
\hline Baseline & 89 & 15 & 15 & 104 & 101 & 17 & 17 & 118 \\
\hline 6-wk follow-up & 88 & 16 & 16 & 104 & 102 & 16 & 16 & 118 \\
\hline 6-mo follow-up & 90 & 14 & 14 & 104 & 102 & 16 & 16 & 118 \\
\hline 12-mo follow-up & 82 & 22 & 22 & 104 & 91 & 27 & 27 & 118 \\
\hline
\end{tabular}

SF-6D, Short-Form Six-Dimension. *Acute hospital days: Indicate postoperative hospital stay in the parent surgical unit/hospital (Papworth or Freeman Hospital, UK). Rehabilitation days: Indicate stay in a local district general hospital/nursing home/convalescence home prior after transfer from the surgical unit but prior to final discharge home. 


\begin{tabular}{|c|c|c|c|c|c|}
\hline \multirow[b]{2}{*}{ Primary admission costs } & \multirow[b]{2}{*}{$\begin{array}{c}\text { Unit of } \\
\text { measurement }\end{array}$} & \multicolumn{2}{|c|}{ Full sternotomy } & \multicolumn{2}{|c|}{ Mini-sternotomy } \\
\hline & & Observations & $\begin{array}{c}\text { Mean (SD) } \\
\text { resource use/ } \\
\text { patient }\end{array}$ & Observations & $\begin{array}{c}\text { Mean (SD) } \\
\text { resource use/ } \\
\text { patient }\end{array}$ \\
\hline Theatre & Minutes & 104 & $191.19(62.15)$ & 118 & $221.11(102.65)$ \\
\hline Critical care (intensive therapy unit) & Hours & 104 & $34.52(56.91)$ & 118 & $55.24(94.69)$ \\
\hline Cardiac ward & Days & 104 & $7.07(4.29)$ & 118 & $6.90(3.87)$ \\
\hline Rehabilitation* & Days & 104 & $2.42(11.84)$ & 118 & $1.66(10.22)$ \\
\hline Acute hospital* & Days & 104 & $0.89(4.95)$ & 118 & $0.77(5.08)$ \\
\hline Physiotherapy (inpatient) & Days & 104 & $5.88(4.20)$ & 118 & $5.94(5.15)$ \\
\hline Occupational therapy (inpatient) & Days & 104 & $0.17(0.58)$ & 118 & $0.24(0.69)$ \\
\hline \multicolumn{6}{|l|}{ Follow-up (postdischarge) } \\
\hline Intensive therapy unit & Days & 104 & $0.00(0.00)$ & 118 & $0.03(0.28)$ \\
\hline General ward & Days & 104 & $2.61(13.55)$ & 118 & $0.77(3.20)$ \\
\hline Cardiac ward & Days & 104 & $0.38(1.43)$ & 118 & $1.19(4.14)$ \\
\hline 24-h blood pressure monitoring & Number of tests & 104 & $0.18(0.52)$ & 118 & $0.17(1.13)$ \\
\hline Radiography (chest) & Number of tests & 104 & $0.55(0.87)$ & 118 & $0.61(0.83)$ \\
\hline Computed tomography scan & Number of tests & 104 & $0.16(0.48)$ & 118 & $0.16(0.49)$ \\
\hline Transthoracic echocardiography & Number of tests & 104 & $0.42(0.66)$ & 118 & $0.56(0.79)$ \\
\hline Transesophageal echocardiography & Number of tests & 104 & $0.02(0.20)$ & 118 & $0.05(0.19)$ \\
\hline Stress echocardiography & Number of tests & 104 & $0.01(0.10)$ & 118 & $0.01(0.09)$ \\
\hline 24-h electrocardiography & Number of tests & 104 & $0.13(0.41)$ & 118 & $0.16(0.44)$ \\
\hline 12-h electrocardiography & Number of tests & 104 & $0.72(0.85)$ & 118 & $0.94(1.17)$ \\
\hline Exercise tolerance test & Number of tests & 104 & $0.07(0.24)$ & 118 & $0.06(0.23)$ \\
\hline Magnetic resonance imaging & Number of tests & 104 & $0.02(0.15)$ & 118 & $0.06(0.22)$ \\
\hline Full pulmonary function testing & Number of tests & 104 & $0.06(0.22)$ & 118 & $0.03(0.16)$ \\
\hline Blood testing & Number of tests & 104 & $0.06(0.21)$ & 118 & $0.07(0.33)$ \\
\hline Accident and emergency visit & Number of visits & 104 & $0.13(0.31)$ & 118 & $0.24(0.50)$ \\
\hline Arrhythmia clinic & Number of visits & 104 & $0.02(0.14)$ & 118 & $0.00(0.00)$ \\
\hline Cardiac rehabilitation & Number of visits & 104 & $1.07(2.78)$ & 118 & $0.34(1.36)$ \\
\hline Cardiology clinic & Number of visits & 104 & $0.47(0.62)$ & 118 & $0.52(0.72)$ \\
\hline General practitioner home visits & Number of visits & 104 & $0.27(0.64)$ & 118 & $0.25(0.68)$ \\
\hline General practitioner visits & Number of visits & 104 & $2.00(2.16)$ & 118 & $2.17(2.18)$ \\
\hline Nurse (specialist community) home visits & Number of visits & 104 & $0.38(1.06)$ & 118 & $0.47(1.22)$ \\
\hline Nurse (general practice) visits & Number of visits & 104 & $1.93(8.83)$ & 118 & $0.71(1.32)$ \\
\hline Occupational therapy & Number of visits & 104 & $0.15(0.70)$ & 118 & $0.05(0.55)$ \\
\hline Pacemaker & Number of visits & 104 & $0.06(0.59)$ & 118 & $0.08(0.39)$ \\
\hline Physiotherapy (home) & Number of visits & 104 & $0.05(0.32)$ & 118 & $0.00(0.00)$ \\
\hline Physiotherapy & Number of visits & 104 & $0.05(0.20)$ & 118 & $0.02(0.11)$ \\
\hline Wound clinic & Number of visits & 104 & $0.06(0.28)$ & 118 & $0.03(0.15)$ \\
\hline
\end{tabular}

$S D$, Standard deviation. *Discharged to convalescence/long-term care/acute hospital instead of home. 
TABLE E21. Summary of deterministic sensitivity and scenario analyses undertaken

\begin{tabular}{|c|c|}
\hline Sensitivity analyses & Rationale \\
\hline Complete-case analysis & $\begin{array}{l}\text { Including only respondents with no missing values across all variables and across follow-up; results in sample } \\
\text { requiring no missing value imputation }\end{array}$ \\
\hline $\begin{array}{l}\text { Excluding patients who died } \\
\text { during primary admission }\end{array}$ & $\begin{array}{l}\text { Patients who died during primary admission were the main cost driver and required substantial surgical time } \\
\text { and cardiac care to assess whether excluding these patients would change recommendations. }\end{array}$ \\
\hline $\begin{array}{l}\text { Excluding additional equipment } \\
\text { cost required }\end{array}$ & Assuming that the additional equipment required for the surgeries already exists in the trusts. \\
\hline Excluding follow-up resource use & $\begin{array}{l}\text { To test the assumption that the cost difference between the two arms were accrued during primary admission, } \\
\text { to allow comparison with literature that missed these costs, but still retain benefits as captured in other studies }\end{array}$ \\
\hline $\begin{array}{l}\text { Excluding follow-up resource use } \\
\text { and utility data }\end{array}$ & $\begin{array}{l}\text { Data up to discharge had few missing values; also to assess impact of having a shorter cutoff time point for trial } \\
\text { (as wider literature had) but provide a less biased analysis that measures benefits but not costs. }\end{array}$ \\
\hline Use SF-6D utility values & SF-6D values used as an alternative construction for QALYs \\
\hline
\end{tabular}

TABLE E22. Costs per patient up to 12 months postrandomization (with imputation), 2015

\begin{tabular}{|c|c|c|c|c|c|}
\hline \multirow[b]{2}{*}{ Parameter } & \multirow[b]{2}{*}{$\begin{array}{c}\text { Mean } \\
\text { unit cost, } £\end{array}$} & \multicolumn{2}{|c|}{ Full sternotomy } & \multicolumn{2}{|c|}{ Mini-sternotomy } \\
\hline & & Observations & $\begin{array}{c}\text { Mean (SD) } \\
\text { cost per } \\
\text { patient, } £\end{array}$ & Observations & $\begin{array}{c}\text { Mean (SD) } \\
\text { cost per } \\
\text { patient, } £\end{array}$ \\
\hline \multicolumn{6}{|l|}{ Primary admission costs } \\
\hline \multicolumn{6}{|l|}{ Additional surgical items } \\
\hline Horizontal surgical saw & 3138.2 & 104 & $0.0(0.0)$ & 118 & $3.1(0.0)$ \\
\hline Single-use saw blade for mini-sternotomy & 48.0 & 104 & $0.0(0.0)$ & 118 & $48.0(0.0)$ \\
\hline Single-use saw blade for full sternotomy & 15.8 & 104 & $15.8(0.0)$ & 118 & $0.0(0.0)$ \\
\hline Pediatric internal cardioversion paddles & 161.7 & 104 & $0.0(0.0)$ & 118 & $0.2(0.0)$ \\
\hline Reprocessing defibrillator paddles for each surgery & 2.4 & 104 & $2.4(0.0)$ & 118 & $2.4(0.0)$ \\
\hline Internal paddle handle & 670.0 & 104 & $0.0(0.0)$ & 118 & $0.7(0.0)$ \\
\hline Cost of additional surgical items* & & 104 & $16.52(0.0)$ & 118 & $52.0(0.0)$ \\
\hline Theatre & 20.0 & 104 & $3823.8(1243.0)$ & 118 & $4422.2(2053.0)$ \\
\hline Critical care (intensive therapy unit) & 1274.9 & 104 & $1833.8(3023.2)$ & 118 & $2934.2(5029.9)$ \\
\hline Cardiac ward & 388.0 & 104 & $2743.7(1664.0)$ & 118 & $2676.3(1499.9)$ \\
\hline Rehabilitation $\dagger$ & 158.6 & 104 & $384.2(1877.6)$ & 118 & $263.4(1621.3)$ \\
\hline Acute hospital $\dagger$ & 388.0 & 104 & $346.9(1918.9)$ & 118 & $297.5(1971.3)$ \\
\hline Physiotherapy (inpatient) & 12.7 & 104 & $74.5(53.2)$ & 118 & $75.2(65.3)$ \\
\hline Occupational therapy (inpatient) & 12.7 & 104 & $2.1(7.3)$ & 118 & $3.0(8.7)$ \\
\hline Subtotal (primary admission) & - & 104 & $9225.7(6510.8)$ & 118 & $10,723.9(8850.2)$ \\
\hline \multicolumn{6}{|l|}{ Post-primary admission costs } \\
\hline \multicolumn{6}{|l|}{ Hospital admission } \\
\hline Intensive therapy unit & 1274.9 & 104 & $0.0(0.0)$ & 118 & $32.4(352.1)$ \\
\hline General ward & 103.0 & 104 & $268.4(1395.4)$ & 118 & $79.4(329.5)$ \\
\hline Cardiac ward & 388.0 & 104 & $149.2(554.8)$ & 118 & $463.6(1606.4)$ \\
\hline \multicolumn{6}{|l|}{ Tests } \\
\hline 24-h blood pressure monitoring & 61.5 & 104 & $10.9(32.0)$ & 118 & $10.2(69.5)$ \\
\hline Radiography (chest) & 3.5 & 104 & $19.4(30.9)$ & 118 & $21.6(29.5)$ \\
\hline Computed tomography scan & 122.3 & 104 & $19.4(58.6)$ & 118 & $19.7(59.8)$ \\
\hline Transthoracic echocardiography & 83.9 & 104 & $35.1(55.2)$ & 118 & $46.9(66.6)$ \\
\hline Transesophageal echocardiography & 128.5 & 104 & $2.5(25.2)$ & 118 & $6.5(24.3)$ \\
\hline Stress echocardiography & 128.5 & 104 & $1.2(12.6)$ & 118 & $1.1(11.8)$ \\
\hline 24-h electrocardiography & 140.7 & 104 & $18.3(57.2)$ & 118 & $22.7(62.3)$ \\
\hline 12-h electrocardiography & 140.7 & 104 & $101.5(119.6)$ & 118 & $132.9(165.0)$ \\
\hline Exercise tolerance test & 140.7 & 104 & $9.5(34.0)$ & 118 & $8.9(32.6)$ \\
\hline Magnetic resonance imaging & 146.2 & 104 & $3.5(21.3)$ & 118 & $9.3(32.5)$ \\
\hline Full pulmonary function testing & 55.3 & 104 & $3.2(12.4)$ & 118 & $1.6(9.1)$ \\
\hline Blood tests & 3.5 & 104 & $0.0(0.1)$ & 118 & $0.0(0.1)$ \\
\hline
\end{tabular}




\begin{tabular}{|c|c|c|c|c|c|}
\hline \multirow[b]{2}{*}{ Parameter } & \multirow[b]{2}{*}{$\begin{array}{c}\text { Mean } \\
\text { unit cost, } £\end{array}$} & \multicolumn{2}{|c|}{ Full sternotomy } & \multicolumn{2}{|c|}{ Mini-sternotomy } \\
\hline & & Observations & $\begin{array}{c}\text { Mean (SD) } \\
\text { cost per } \\
\text { patient, } £\end{array}$ & Observations & $\begin{array}{c}\text { Mean (SD) } \\
\text { cost per } \\
\text { patient, } £\end{array}$ \\
\hline \multicolumn{6}{|l|}{ Health care visits } \\
\hline Accident and emergency visit & 140.6 & 104 & $18.9(43.0)$ & 118 & $33.4(70.4)$ \\
\hline Arrhythmia clinic & 131.1 & 104 & $2.5(18.1)$ & 118 & $0.0(0.0)$ \\
\hline Cardiac rehabilitation & 97.8 & 104 & $104.4(271.9)$ & 118 & $33.6(133.4)$ \\
\hline Cardiology clinic & 123.0 & 104 & $57.4(76.3)$ & 118 & $63.6(88.1)$ \\
\hline General practitioner home visits & 45.0 & 104 & $12.1(28.9)$ & 118 & $11.3(30.4)$ \\
\hline General practitioner visits & 65.0 & 104 & $129.7(140.6)$ & 118 & $141.3(141.8)$ \\
\hline Nurse (specialist community) home visits & 19.4 & 104 & $7.3(20.6)$ & 118 & $9.0(23.6)$ \\
\hline Nurse (general practice) visits & 14.5 & 104 & $28.0(127.7)$ & 118 & $10.3(19.2)$ \\
\hline Occupational therapy (outpatient) & 16.7 & 104 & $2.5(11.7)$ & 118 & $0.8(9.2)$ \\
\hline Pacemaker & 76.3 & 104 & $4.4(44.9)$ & 118 & $6.1(29.5)$ \\
\hline Physiotherapy (home) & 27.0 & 104 & $1.4(8.6)$ & 118 & $0.0(0.0)$ \\
\hline Physiotherapy (outpatient) & 16.1 & 104 & $0.8(3.4)$ & 118 & $0.3(1.9)$ \\
\hline Wound clinic & 54.9 & 104 & $3.4(15.2)$ & 118 & $1.6(8.3)$ \\
\hline Subtotal (post-primary admission) & - & 104 & $1014.9(1777.5)$ & 118 & $1168.2(2077.9)$ \\
\hline Drugs (total) & - & 104 & $379.4(548.2)$ & 118 & $441.4(976.7)$ \\
\hline Total cost & - & 104 & $10,620.0(7623.8)$ & 118 & $12,333.5(9864.2)$ \\
\hline
\end{tabular}

$S D$, Standard deviation. *Mean cost per patient estimated by assuming that the saw, paddle, and handle have a 20 -year life span and are used in 255 surgeries over a 5 -year period. Defibrillator (paddle, handle and sterilization) cost applicable in only $30 \%$ of cases. $†$ Discharged to convalescence/long-term care/acute hospital instead of home.

TABLE E23. Summary of utility values and QALYs

\begin{tabular}{|c|c|c|c|c|}
\hline \multirow[b]{2}{*}{ Test } & \multicolumn{2}{|c|}{ Full sternotomy } & \multicolumn{2}{|c|}{ Mini-sternotomy } \\
\hline & Observations & Mean (SD) utility & $\overline{\text { Observations }}$ & Mean (SD) utility \\
\hline \multicolumn{5}{|l|}{ EQ-5D } \\
\hline Baseline & 104 & $0.6988(0.24)$ & 118 & $0.7793(0.18)$ \\
\hline $4 \mathrm{~d}$ postoperation & 104 & $0.3721(0.29)$ & 118 & $0.4430(0.28)$ \\
\hline Discharge & 104 & $0.5815(0.23)$ & 118 & $0.5940(0.25)$ \\
\hline 6-wk follow-up & 104 & $0.6930(0.21)$ & 118 & $0.7195(0.24)$ \\
\hline 6-mo follow-up & 104 & $0.8272(0.22)$ & 118 & $0.8322(0.24)$ \\
\hline 12-mo follow-up & 104 & $0.7584(0.29)$ & 118 & $0.8253(0.29)$ \\
\hline EQ-5D QALYs & 104 & $0.7699(0.19)$ & 118 & $0.7978(0.21)$ \\
\hline \multicolumn{5}{|l|}{ SF-6D } \\
\hline Baseline & 104 & $0.6418(0.11)$ & 118 & $0.6802(0.12)$ \\
\hline 6-wk follow-up & 104 & $0.6327(0.10)$ & 118 & $0.6356(0.14)$ \\
\hline 6-mo follow-up & 104 & $0.7184(0.16)$ & 118 & $0.7332(0.19)$ \\
\hline 12-mo follow-up & 104 & $0.6868(0.19)$ & 118 & $0.7058(0.23)$ \\
\hline SF-6D QALYs & 104 & $0.6847(0.12)$ & 118 & $0.6989(0.16)$ \\
\hline
\end{tabular}

$S D$, Standard deviation; $Q A L Y$, quality-adjusted life-years; $S F-6 D$, Short-Form Six-Dimension. 
TABLE E24. Comparison of costs and QALYS (raw data, with imputation)

\begin{tabular}{|c|c|c|}
\hline Parameter & Full sternotomy $(n=104)$ & Mini-sternotomy $(n=114)$ \\
\hline Total costs over 12 mo, $£$, mean (SD) & $10,620(7624)$ & $12,334(9864)$ \\
\hline Incremental cost at 12 mo (MS-FS), $£$ & & 1714 \\
\hline Total EQ-5D 3L QALYs, mean (SD) & $0.7699(0.19)$ & $0.7978(0.21)$ \\
\hline Incremental EQ-5D 3L QALYs (MS-FS) & & 0.0279 \\
\hline ICER, $£$ & & 61,379 \\
\hline INMB at WTP of $£ 20,000 / Q A L Y, £$ & & -1155 \\
\hline INMB at WTP of $£ 30,000 / \mathrm{QALY}, £$ & & -876 \\
\hline
\end{tabular}

$S D$, Standard deviation; $M S$, mini-sternotomy; $F S$, full sternotomy; $Q A L Y$, quality-adjusted life-year; $I C E R$, incremental cost-effectiveness ratio; $I N M B$, incremental net monetary benefit; $W T P$, willingness to pay.

TABLE E25. Regression estimates of costs and QALYs

\begin{tabular}{lcccc}
\hline Dependent variable & Coefficient & SE & $\boldsymbol{P}$ value & $\mathbf{9 5 \%}$ CI \\
\hline EQ-5D QALYs & & & & -87 \\
$\quad$ Mini-sternotomy & -0.0040 & 0.0245 & .31 & -0.0520 to 0.0440 \\
Male sex & 0.0250 & 0.0246 & .00 & -0.0231 to 0.0732 \\
Age & -0.0051 & 0.0014 & .00 & 0.1880 to 0.4194 \\
Baseline EQ-5D score & 0.3037 & 0.0590 & .08 & -0.0107 to 0.1694 \\
Tissue valve & 0.0794 & 0.0459 & .00 & 0.5249 to 0.9533 \\
Constant & 0.7391 & 0.1093 & & -344.82 to 4365.25 \\
Total cost (£) & & & .29 & -3637.73 to 1086.70 \\
Mini-sternotomy & 2010.22 & 1201.57 & .15 & -34.13 to 230.77 \\
Male sex & -1275.52 & 1205.23 & .73 & -6660.34 to 4693.33 \\
Age & 98.32 & 67.58 & .71 & -5271.45 to 3564.60 \\
Baseline EQ-5D score & -983.50 & 2896.40 & .29 & -4804.64 to $16,214.06$ \\
Tissue valve & -853.43 & 2254.14 & 5362.01 & \\
Constant & 5704.71 & &
\end{tabular}

SE, Standard error; $C I$, confidence interval; $Q A L Y$, quality-adjusted life-year. 
TABLE E26. Deterministic sensitivity analysis using difference MS-FS, adjusted for baseline

\begin{tabular}{|c|c|c|c|c|c|c|}
\hline Parameter & Obs & $\begin{array}{c}\text { Incremental } \\
\text { cost over } \\
12 \text { months (MS-FS), } \\
£, \text { mean (SE) }\end{array}$ & $\begin{array}{c}\text { Incremental } \\
\text { QALYs over } \\
12 \text { months } \\
\text { (MS-FS), £, mean (SE) }\end{array}$ & ICER, $£$ & $\begin{array}{c}\text { INMB at } \\
£ 20,000 \text { per } \\
\text { QALY, } £\end{array}$ & $\begin{array}{l}\text { INMB at } \\
£ 30,000 \text { per } \\
\text { QALY, } £\end{array}$ \\
\hline Missing values imputed by PMM & 222 & $2010(1202)$ & $-0.0040(0.0245)$ & Dominated & -2089.26 & -2128.78 \\
\hline Using SF-6D QALYs & 222 & $2010(1202)$ & $-0.0017(0.0178)$ & Dominated & -2044.44 & -2061.55 \\
\hline $\begin{array}{l}\text { Assuming there is no additional equipment } \\
\text { required for the } 2 \text { procedures }\end{array}$ & 222 & $1975(1202)$ & $-0.0040(0.0245)$ & Dominated & -2053.73 & -2093.26 \\
\hline Excluding follow-up resource use & 222 & $1664(1060)$ & $-0.0040(0.0245)$ & Dominated & -1742.98 & -1782.50 \\
\hline Complete-case analysis & 90 & $-150(661)$ & $-0.0145(0.0334)$ & $10,333.62$ & -139.89 & -284.60 \\
\hline $\begin{array}{l}\text { Excluding patients who died during } \\
\text { primary admission }\end{array}$ & 219 & $1408(1128)$ & $0.0172(0.0216)$ & $81,905.62$ & -1064.40 & -892.46 \\
\hline $\begin{array}{l}\text { Including costs and QALY data } \\
\text { only up to discharge }\end{array}$ & 222 & $1664(1060)$ & $0.0013(0.0009)$ & $1,316,409.02$ & -1638.66 & -1626.02 \\
\hline
\end{tabular}

$O b s$, Observed number of patients; $M S$, mini-sternotomy; $F S$, full sternotomy; $S E$, standard error; $Q A L Y$, quality-adjusted life-year; $I C E R$, incremental cost-effectiveness ratio; $I N M B$, incremental net monetary benefit; $P M M$, predictive mean matching; SF-6D, Short-Form Six-Dimension.

TABLE E27. Probabilistic sensitivity analysis using difference MS-FS, adjusted for baseline

\begin{tabular}{|c|c|c|c|c|c|c|}
\hline Parameter & Obs & $\begin{array}{c}\text { Incremental } \\
\text { cost over } 12 \text { months } \\
\text { (MS-FS), } £, \\
\text { mean }(\mathrm{SE})\end{array}$ & $\begin{array}{c}\text { Incremental QALYs } \\
\text { over } 12 \text { months } \\
\text { (MS-FS), } £, \\
\text { mean (SE) }\end{array}$ & ICER, £ & $\begin{array}{l}\text { INMB at } \\
£ 20,000, £\end{array}$ & $\begin{array}{l}\text { INMB at } \\
£ 30,000, £\end{array}$ \\
\hline Missing values imputed by PMM and adjusted & 1000 & $2154(36)$ & $-0.0122(0.0008)$ & Dominated & -2396.99 & -2518.59 \\
\hline Using SF-6D QALYs & 1000 & $2154(36)$ & $-0.0075(0.0006)$ & Dominated & -2303.03 & -2377.66 \\
\hline $\begin{array}{l}\text { Assuming there is no additional equipment } \\
\text { required for the two procedures }\end{array}$ & 1000 & $2245(40)$ & $-0.0096(0.0008)$ & Dominated & -2437.25 & -2533.50 \\
\hline Excluding follow-up resource use & 1000 & $1835(35)$ & $-0.0131(0.0008)$ & Dominated & -2096.58 & -2227.15 \\
\hline Complete-case analysis & 1000 & $-111(22)$ & $-0.0121(0.0011)$ & 9170.78 & -130.56 & -251.12 \\
\hline $\begin{array}{l}\text { Excluding patients who died during } \\
\text { primary admission }\end{array}$ & 1000 & $1433(32)$ & $0.0147(0.0007)$ & $97,425.25$ & -1138.55 & -991.50 \\
\hline $\begin{array}{l}\text { Including costs and QALY data only } \\
\text { up to discharge }\end{array}$ & 1000 & $1835(35)$ & $0.0008(0.0000)$ & $2,415,384.92$ & -1820.25 & -1812.65 \\
\hline
\end{tabular}

